\title{
LA TRANSFORMACIÓN DEL ESPACIO DOMÉSTICO COMO RESULTADO DE CAMBIOS EN EL ESPACIO PÚBLICO EN MALATA, UNA DOCTRINA COLONIAL TEMPRANA EN EL VALLE DEL COLCA
}

\author{
Abel Traslavina ${ }^{\mathrm{a}}$
}

\begin{abstract}
Resumen
La llegada de los españoles al valle del Colca no solo repercutió en la esfera de lo público, sino que además las poblaciones nativas se vieron ciertamente influenciadas por ello. Si bien existen registros de estas poblaciones en la manera de visitas y otro tipo de documentación, no se conoce la naturaleza de aquellos cambios que trajo consigo la aplicación del discurso politico-religioso desde el estudio de su cultura material. Tomando como base algunos casos de organización doméstica, se delinean las características de los poblados del valle alto del Colca, lo que se traduce en el análisis del diseño de su trazo, a partir del estudio sistemático de una doctrina cristiana temprana: Malata. De esta manera, se explora la transformación de elementos propios del espacio doméstico, así como su organización, a partir de cambios en el espacio público, lo que nos brinda nuevas luces sobre aquellas poblaciones nativas y su transformación previa al establecimiento de las reducciones toledanas.
\end{abstract}

Palabras clave: valle del Colca, Periodo Colonial Temprano, análisis arquitectónico, arquitectura doméstica y pública

Abstract

THE TRANSFORMATION OF DOMESTIC SPACE AS THE RESULT OF CHANGES IN PUBLIC SPACE IN MALATA, AN EARLY COLONIAL DOCTRINE IN THE COLCA VALLEY

The arrival of the Spaniards to the Colca Valley not only had repercussions in the public sphere but also the native populations were deeply influenced. Notwithstanding the records of these populations in the form of visitas (censuses) and other documentation, the nature of those changes brought about by the application of political-religious discourse on their material culture is unknown. This article aims to further the knowledge of this context of change, through defining the characteristics of the late prehispanic villages of the upper Colca valley and the architectural analysis of Malata, an early Christian doctrina, to understand the transformation of the domestic space based on changes in the public space over the time.

Keywords: Colca Valley, Early Colonial Period, architectural analysis, domestic and public architecture

${ }^{a}$ Departamento de Antropología, Vanderbilt University

Correo electrónico: abel.traslavina@vanderbilt.edu 
«Las fuentes no-escritas son aún escasas. Hace falta una arqueología de los asentamientos civiles (no-monumentales), es decir, de las aldeas rurales que sean pre-hispánicas o coloniales».

Thierry Saignes (1991: 95)

\section{Introducción}

La cita que da inicio a este texto expresa la necesidad de recurrir a la arqueología como fuente complementaria de los documentos para aproximarnos al conocimiento de las poblaciones nativas, pero yendo más allá de las evidencias «monumentales». Pero, ¿cómo lograr aproximarnos a esta visión más integral que recomienda Saignes? A continuación, se plantea una alternativa de estudio, a través de la arqueología y el estudio de la materialidad en procura de complementar el panorama sobre las poblaciones nativas y su situación durante los primeros ańos de la ocupación peninsular. Empecemos por señalar algunos aspectos relevantes para comprender los alcances de las investigaciones sobre el discurso político-religioso hispano impuesto en los Andes, abordado por una serie de investigadores desde distintas disciplinas. En el caso de la etnohistoria, investigadores como Franklin Pease y Alejandro Málaga Medina han documentado las acciones del régimen toledano para promover e institucionalizar una serie de transformaciones en el espacio andino. Tales acciones, que tienen sus antecedentes más tempranos en Centroamérica y México, implicaron el reasentamiento masivo de indígenas en los Andes y su concentración en nuevos pueblos, como figura en documentación de la época. Sin embargo, las fuentes documentales son limitadas en cuanto información que pueden ofrecer sobre el establecimiento de las reducciones en cada caso, como ha sido señalado de manera pertinente por Franklin Pease: «Hay un problema adicional aquí: no sabemos bien cómo fueron hechas las reducciones; tampoco en Yanque [...] Hasta la fecha, la información a nuestro alcance sobre las reducciones nos indica muchas veces qué ayllus fueron ubicados en ellas, pero esto no es suficiente; más aún, nos da un indicio de la inseguridad de la información» (1977: 159). Más adelante, Pease insiste también en la escasez o ausencia de información de la siguiente manera:

La visita general del virrey Toledo explica la presencia de las reducciones también en el área del Colca, aunque las reducciones mismas se iniciaron en el Perú desde años antes. Los estudios sobre éstas sufren hasta ahora de una situación fundamental: el no haber a la mano hasta hoy un solo protocolo de reducción, que explique cuáles fueron las razones —en cada caso diferentes e importantes- a que recurrieron los visitadores para decidir el lugar en el que se haría un nuevo asentamiento de la población, y en el cual haya también alguna referencia — nuevamente específica en cada caso- a los criterios que presidieron la reunión (o la dispersión) de ciertos grupos de parentesco (ayllu), vecinos en una región. En el caso del valle del Colca, asentamiento central de los Collaguas, tenemos un conjunto de reducciones no relacionadas en los resúmenes generales de la visita toledana (Málaga 1974: 60 ss.; Cook 1975: 215 ss.), donde sólo se indicó el número de habitantes y las tasas correspondientes (ibid.: 166).

Por otro lado, desde la arquitectura, estudiosos como Ramón Gutiérrez han abordado los aspectos formales de la aplicación de tales directrices, en términos del programa urbano (la organización, la traza y la articulación de los asentamientos) y arquitectónico (las características particulares de los edificios) de los nuevos poblados, a través del estudio de iglesias, casonas y demás edificaciones virreinales. Sin embargo, muchos de los estudios se llevan a cabo en contextos urbanos y rurales, que, si bien se iniciaron como reducciones, han sufrido una serie de modificaciones debido a que siguen siendo habitados en la actualidad, lo cual hace más difícil percibir, registrar y analizar el diseño original y sus transformaciones a través del tiempo, tanto en la esfera de lo público como lo residencial. 
De acuerdo con este panorama, los aportes desde la arqueología han sido escasos; sin embargo, en la última década, han ido incrementando gratamente, como se puede observar con los artículos que integran este volumen. Siguiendo esa línea, este artículo busca complementar los alcances ofrecidos hasta ahora por otras disciplinas, con énfasis en la dimensión de lo material y lo espacial, de los contextos específicos y de cómo éstos han variado a través del tiempo. De esta manera, esta perspectiva desde la arqueología puede contribuir a la comprensión de las estrategias de reordenamiento territorial adoptadas por el régimen hispano, que fueron perfeccionándose hasta ser estandarizadas e institucionalizadas por Francisco de Toledo desde su arribo en 1569 y a lo largo de la década de 1570.

Para entender mejor estas estrategias originadas en Centroamérica y México, es necesario mencionar algunas de ellas a través de los documentos oficales. En este punto, es posible mencionar las instrucciones dadas por los reyes de España a fray Nicolás de Ovando, enviadas el 16 de setiembre de 1501. En estas, se percibe en los reyes el espíritu inicial de incentivar a que los nativos lleven una vida conforme a las prácticas religiosas establecidas: «[...] deseamos que los yndios se conviertan a nuestra Sancta Fee Cathólica, e sus ánimas se salven, porque éste es el mayor bien que les podemos desear, para lo qual es menester que sean ynformados en las cosas de nuestra fee, para que vengan en conoscimiento della, ternéys muncho cuidado de procurar, sin les facer fuerza alguna, como los religiosos que allá están los ynformen e amonesten para ello con muncho amor, de manera que, lo más presto que se pueda, se conviertan; e para ello daréys todo el favor e ayuda que menester sea» (Instrucciones al comendador fray Nicolás de Ovando... 1501).

Cerca de dos años después, el 29 de marzo de 1503, las nuevas instrucciones de la Corona, sustentadas en las exigencias de la conversión a la fe cristiana, inciden claramente en la reconfiguración del estilo de vida de las poblaciones nativas:

[...] por lo que comple a la salvación de las ánimas de los dichos yndios en la contratación de las xentes que allá están, es necesario que los yndios se reunan en pueblos en que vivan xuntamente, e que los unos non estén nin anden apartados de los otros por los montes, e que allí thengan cada uno dellos su casa abitada con su muxer e fixos e eredades, en que labren e siembren e crien sus ganados; e quen cada pueblo de los que se ficieren, faya iglesia e capellán, que thenga cargo de los dotrinar e enseñar en nuestra Sancta Fee Cathólica; (...) facer que se fagan poblaciones en que los dichos yndios puedan estar e estén xuntos [...] que cada uno de los dichos yndios thenga su casa apartada en que moren su muxer e fixos [...] se faga iglesia en cada una de las dichas poblaciones, que si se ficieren para quen ellas se diga e celebren los domingos oficios, e quen cada una dellas se ponga un capellán. (Op. cit:: 390-395, el énfasis es propio, cursivas mías).

Por otro lado, desde la arquitectura, estudiosos como Ramón Gutiérrez han abordado los aspectos formales de la aplicación de tales directrices, en términos del programa urbano (la organización, la traza y la articulación de los asentamientos) y arquitectónico (las características particulares de los edificios) de los nuevos poblados, a través del estudio de iglesias, casonas y demás edificaciones virreinales. Sin embargo, muchos de los estudios se llevan a cabo en contextos urbanos y rurales, que, si bien se iniciaron como reducciones, han sufrido una serie de modificaciones debido a que siguen siendo habitados en la actualidad, lo cual hace más difícil percibir, registrar y analizar el diseño original y sus transformaciones a través del tiempo, tanto en la esfera de lo público como lo residencial.

De acuerdo con este panorama, los aportes desde la arqueología han sido escasos; sin embargo, en la última década, han ido incrementando gratamente, como se puede observar con los artículos que integran este volumen. Siguiendo esa línea, este artículo busca complementar los alcances ofrecidos hasta ahora por otras disciplinas, con énfasis en la dimensión de lo material y lo espacial, de los contextos específicos y de cómo éstos han variado a través del tiempo. De esta manera, esta perspectiva desde la arqueología puede contribuir a la comprensión de las estrategias de reordenamiento territorial adoptadas por el régimen hispano, que fueron perfeccionándose hasta ser estandarizadas e institucionalizadas por Francisco de Toledo desde su arribo en 1569 y a lo largo de la década de 1570. 
Para entender mejor estas estrategias originadas en Centroamérica y México, es necesario mencionar algunas de ellas a través de los documentos oficales. En este punto, es posible mencionar las instrucciones dadas por los reyes de Espańa a fray Nicolás de Ovando, enviadas el 16 de setiembre de 1501. En estas, se percibe en los reyes el espíritu inicial de incentivar a que los nativos lleven una vida conforme a las prácticas religiosas establecidas: «[...] deseamos que los yndios se conviertan a nuestra Sancta Fee Cathólica, e sus ánimas se salven, porque éste es el mayor bien que les podemos desear, para lo qual es menester que sean ynformados en las cosas de nuestra fee, para que vengan en conoscimiento della, ternéys muncho cuidado de procurar, sin les facer fuerza alguna, como los religiosos que allá están los ynformen e amonesten para ello con muncho amor, de manera que, lo más presto que se pueda, se conviertan; e para ello daréys todo el favor e ayuda que menester sea» (Instrucciones al comendador fray Nicolás de Ovando... 1501).

Cerca de dos años después, el 29 de marzo de 1503, las nuevas instrucciones de la Corona, sustentadas en las exigencias de la conversión a la fe cristiana, inciden claramente en la reconfiguración del estilo de vida de las poblaciones nativas:

[...] por lo que comple a la salvación de las ánimas de los dichos yndios en la contratación de las xentes que allá están, es necesario que los yndios se reunan en pueblos en que vivan xuntamente, e que los unos non estén nin anden apartados de los otros por los montes, e que alli thengan cada uno dellos su casa abitada con su muxer e fixos e eredades, en que labren e siembren e crien sus ganados; e quen cada pueblo de los que se ficieren, faya iglesia e capellán, que thenga cargo de los dotrinar e enseñar en nuestra Sancta Fee Cathólica; (...) facer que se fagan poblaciones en que los dichos yndios puedan estar e estén xuntos [...] que cada uno de los dichos yndios thenga su casa apartada en que moren su muxer e fixos [...] se faga iglesia en cada una de las dichas poblaciones, que si se ficieren para quen ellas se diga e celebren los domingos oficios, e quen cada una dellas se ponga un capellán. (Instrucción para el gobernador y oficiales sobre el gobierno de las Indias... 1503, cursivas mías).

En el pasaje anterior es posible notar que las estrategias de la Corona no solo pretendieron modificar las prácticas cotidianas de los indígenas, sino que además se procuró transformar el espacio físico, su orden y dinámica. Ese nuevo orden se establece incluso en la organización misma de las personas al interior de nuevos poblados en donde distintos grupos étnicos eran reasentados en un mismo lugar «sin que los de la una población puedan facer dapño a los de la otra, nin los de la otra a la otra» (ibid.).

De esta manera, las estrategias de dominio se materializaron, por un lado, en la construcción de nuevos poblados, diseñados para diferenciar e individualizar a los grupos indígenas que fueron reasentados, poniendo énfasis en el registro de cada familia. En tal sentido, la «casa» funcionó como la unidad mínima de registro poblacional y de sus respectivas posesiones. Por otro lado, se incluyó la construcción de edificaciones no domésticas encargadas de ejercer control sobre ellos y de asegurarles una vida más acorde con los preceptos de la iglesia.

Años después la Corona envió instrucciones a don Diego Colón, gobernador de La Española, el 3 de mayo de 1509, a través de las cuales ordena la fundación de pueblos de indios. De este modo, queda en evidencia la preocupación de la Corona por la posibilidad de que los indios puedan apropiarse de bienes españoles (Solano 1995). Años después, el 23 de enero de 1513, «Las ordenanzas para el tratamiento de los indios, ordenadas por los Reyes Católicos, Isabel I de Castilla y Fernando II de Aragón, V de España» señalan una serie de enunciados dirigidos al gobierno de La Española (actuales territorios de República Dominicana y Haití), que enfatizan en los problemas que generan los nativos por «[...] tener sus asientos y estançias tan lexos como los tyenen y apartados de los logares donde viben los españoles que de acá an ydo y van a poblar a la dicha ysla [...]» (Las ordenanzas para el tratamiento de los indios, ordenadas por los Reyes Católicos... 1513). Dados estos problemas, la intención de la Corona fue condicionar a los nativos a ciertos parámetros de vivienda, mediante los cuales se determinaron dimensiones, provisiones de alimentos y otros suministros de manera específica: «Primeramente fordenamos e mandamos que por quanto es nuestra determinaçión de mudar los dichos yndios y facerles estançias junto con las de los españoles, que ante todas 
cossas las personas a quien están encomendados o se encomendaren los dichos yndios, para cada cincuenta yndios fagan luego quatro bohíos cada uno de a XXX pies de largo e quinze de ancho e $\mathrm{V}$ mil montones, los tres mil de yuca y los dos mill de ajes e doscientos e cinquenta pies de axí e cinquenta pies de algodón, y asy por este res/peto creçiendo y menguando según la cantydad de los yndios que tovyere encomendados [...]» (idem).

Lo hasta ahora señalado en el pasaje anterior se integra a la construcción de edificios de funciones complementarias a las domésticas, tal como en el pasaje desarrollado previamente. Además, añade algunos muebles que complementan los atributos propios de dichas edificaciones, como se expresa a continuación: "Ansymismo, hordenamos y mandamos quel vesino a quien se encomendaren los dichos yndios sea obligado de les tener fecha una casa para yglesia [...] en la qual dicha yglesia ponga ymágenes de Nuestra Señora y una/ campanilla para los llamar a resar [...]» (idem).

Finalmente, podemos añadir que se incide en la modificación de los hábitos, de las prácticas cotidianas y del establecimiento de algunas prohibiciones para los nativos:

la persona que los tovyere encomendados sea obligado a los haser llamar en anocheciendo con la campana e yr con ellos a la tal yglesia e haseles synar e santyguar y todos juntos desyr el ave maria y pater noster, $y$ credo y salve regina [...] e que asymismo les enseñe los diez mandamientos e syete pecados mortales y los artyculos de la fe a los que a la tal persona pareciere que tengan capaçidad e avilidad para los aprender, pero esto sea con mucho amor e dulçura, e la tal persona que asy no lo cunpliere yncurra en seis pesos de oro de pena, los dos para la nuestra Cámara e los otros dos para el que lo acussare, e los otros dos para el juez que lo sentençiare y executare, la qual dicha pena mando que executen [...] que en las estançias los españoles e yndios que en ellas resyden están mucho tienpo syn oyr misa y es rasón que la oygan, a lo menos las pascoas e domyngos y fiestas y en cada estançia no podrá aver clérigos para desyr misa, hordenamos y mandamos que [...] en la estançia que más en comarca estoviere de todas las tras se haga una yglesia, en la qual yglesia pongan ymágenes de Nuestra Señora y cruzes. (idem, cursivas mías).

Un caso interesante y que puede contribuir a evidenciar las estrategias de ocupación hispana es la fundación del pueblo de San Francisco de Acámbaro (México). La fundación de este nuevo pueblo se habría iniciado el 19 de setiembre de 1526, en donde se instaló «[...] cruz alta de cinco brazadas de alto, de madera de sabino [...] una ermita y dos palos altos, uno arriba atravesado, onde (sic) se colgaron las dos campanas; y domingo, a veinte de Septiembre, celebró la misa de Espíritu Santo el padre y señor Don Juan Bautista, cura y vicario del pueblo de Tula [...]» (Sánchez Del Olmo, 2006: 769 citado de: Beaumont, P.: Crónica de los Santos Apóstoles S. Pedro y S. Pablo... [6] Capítulo I, p. 28). Este dato guardaría coherencia, a decir de Sánchez (op. cit.: 768), con lo narrado en la "Relación de la Villa de Celaya y su partido», en la que se señala que el pueblo de Acámbaro tenía árboles muy grandes llamados sabinos (op. cit.: 768). Todos estos elementos permiten tener una idea más clara sobre la fundación de un pueblo de indios, desde la programación de actividades preeminentemente religiosas hasta la construcción o elaboración tanto de instalaciones como de artefactos y demás objetos para tal fin, lo que va más allá del mismo acto fundacional, pero que se relaciona íntimamente con él. Además de la construcción de edificios, vemos que se habría puesto énfasis también en la traza general del nuevo pueblo, en donde se «(...) echaron cinco calles desde onde (sic) están el río grande hasta la parte Sur, onde (sic) están unos cerritos, y las otras cinco calles empezó al pie del cerro grande para la parte del Poniente, que hacen diez calles cuadrado (...)» (idem.). Esto quiere decir que o se aprovechó el trazo de un poblado anterior al que se le hizo algunas adiciones, o se modificó parte considerable del mismo. En todo caso, se habría reconfigurado el espacio tanto por las nuevas calles como por la construcción de edificios de eminente función no doméstica, tal como hemos visto que se estipula en los pasajes antes citados en otros lugares.

A partir de esta información, es posible plantear la superposición de poblados en donde la construcción de calles se constituye en una estrategia de singular importancia por permitir ordenar los flujos de tránsito al interior del asentamiento. Adicionalmente, resulta interesante ver que esta reorganización es ejecutada por franciscanos, pero teniendo en cuenta las ideas provenientes 
de la Corona española. Esto refleja cómo el poder político y el religioso se complementan para materializar su discurso en la construcción de los pueblos de indios como una entidad que sirva a ambos fines. Esto es lo que habría sucedido con el pequeño poblado de Malata, objeto de la presente investigación. De esta manera los pueblos de indios serán objeto de un ordenamiento en el que quedan imbricados tanto el orden material o arquitectónico como el civil y social. En ese sentido, resulta interesante lo narrado en la "Real cédula de Carlos I para que se pongan en policía los indios», emitida el 23 de agosto de 1538, en la que se promueve expresamente ese nuevo orden: «[...] para que nuestra santa fe católica sea ampliada entre los indios naturales desa tierra, y más aprovechen en ella, sería necesario ponerlos en policía humana para que sea camino y medio de darles a conocer la divina, y que para esto se debría dar orden como viviesen juntos en sus calles y plazas concertadamente y que desta manera los perlados podrían tener más entero conocimiento de las cosas de los dichos naturales y verían y sabrían la manera y mejor orden que con ellos se podría tener para su bien y doctrina [...]» (Real cédula de Carlos I para que se pongan en policía los indios... 1538). En este pasaje, se expresa la intención de subordinar a los nativos a ese nuevo régimen expresado en "calles y plazas», a partir de lo cual queda en evidencia el correlato material - al menos como propuesta - del discurso que se plantea. De este modo, se colige que aquella "policía humana» a la que se hace referencia tiene una expresión física cuyo ordenamiento y puesta en práctica, si bien aún en ciernes, es consecuencia directa e indispensable del discurso que la sustenta.

\section{Un acercamiento a los asentamientos tardíos en el valle del Colca}

La dimensión de lo doméstico para el caso Collagua muestra una relativa homogeneidad desde el espacio construido, que se refleja en "el patrón arquitectónico Collagua», definido sobre la base de su mampostería, la forma y altura de sus hastiales, y la forma y dimensiones de sus vanos de acceso, con las respectivas variantes de su forma en planta (Neira 1961; Guerra y Aquize 1996; Brooks 1998; Wernke 2003, 2009, 2013a, 2013b). Siguiendo estos atributos, no se observan diferencias que vayan más allá de la factura misma de los edificios en cuanto a la elaboración y selección diferencial de los materiales, elementos que sugerirían un mayor estatus de unos conjuntos arquitectónicos frente a otros.

Partiendo de ello, dentro de lo conocido en las últimas décadas de ocupación previas al arribo peninsular del valle alto del Colca, la lectura que se tiene de los asentamientos desde la arquitectura muestra que tal homogeneidad se ve ligeramente vulnerada en su trazo por foráneos elementos cusqueños, en la forma de ubicuas kallanka, asociadas a plazas que tienden a situarse en los sectores preeminentes de tales asentamientos (Wernke 2003, 2006, 2009, 2013a, 2013b; Traslaviña 2009, 2016; Traslaviña y Wernke 2014).

Tal distribución de edificios inka se relaciona con la presencia de otro tipo de edificios, también foráneos, establecidos durante la inicial ocupación peninsular: estructuras de forma rectangular con un único acceso en uno de los ejes cortos, a veces con arreglos adicionales como la presencia de hastiales o incluso muros frontales que delimitan un espacio anterior (nártex). Han sido identificados como edificios religiosos tempranos (capillas), cuya presencia en esta parte del valle del Colca habría ocurrido desde mediados del siglo XVI en torno a las kallanka (Wernke 2013a, 2013b, 2009, 2006, 2003; Traslavińa 2009, 2016; Traslavińa y Wernke 2014).

La presencia de estas capillas estaría vinculada con un cambio inicial que, además de la obvia modificación de la esfera de lo público (lo político y religioso), repercutiría en la esfera de lo doméstico. Como se ha mencionado, esa aparente homogeneidad en cuanto a los edificios como unidades constructivas y los conjuntos de ellos como unidades mínimas de expresión del espacio doméstico se configuran, a grandes rasgos, como un aspecto uniforme dentro de la organización espacial local. En ese contexto, la terraza desempeńa el papel de soporte, dado lo abrupto de la geografía del valle. Es entonces que el espacio doméstico, definido por la terraza, presenta distintos arreglos que solo varían en el número, tamaño y disposición de los edificios que lo conforman, así como los muros que convergen para formar espacios menores. Por lo tanto, el concepto básico 
que es posible percibir permanece invariable: grupos de edificios relativamente homogéneos en torno a áreas abiertas. Estos aspectos serán ilustrados en los siguientes casos a continuación.

\subsection{Uskallacta}

Llamado también Juskallacta, se encuentra dentro de los límites del distrito de Chivay, en una ladera de pendiente moderada a abrupta, en la margen izquierda del valle del Colca, a un lado de la carretera que comunica Chivay y Yanque. Brooks (1998: 228) refiere que, según las fotografías aéreas de 1974, habrían existido un total de entre 90 a 95 «casas» o sus bases; sin embargo, en su visita al lugar en 1994, ella contó solo 82, que registró en siete sectores a lo largo de una amplia ladera. Aproximadamente, 10 de ellas han desaparecido posiblemente como consecuencia de las labores de construcción del canal Majes y su acceso al Túnel 5. Más adelante, Brooks (ibid:: 230) explica que, en este asentamiento, la forma común de las "casas» es la rectangular, que en uno de sus lados largos presenta un único acceso, alto y estrecho. Además, está compuesta por un espacio interior simple con una eventual presencia de nichos sin ventanas y los techos están definidos por hastiales a dos aguas.

De otro lado, Guerra y Aquize (1996: 56-61) aseguran que existen 60 «unidades arquitectónicas», que se distribuyen en dos sectores: 24 en la parte baja, o Sector A, y 36 en el Sector B, mejor conservado. En relación con el sector bajo, sostienen que la construcción de un estanque, relacionado con infraestructura del Proyecto Majes-Siguas, habría destruido posiblemente más edificios. Adicionalmente a lo señalado por Brooks, estos autores sostienen que prácticamente todas las estructuras habrían tenido dos plantas, pues sólo una o dos de ellas presentarían una sola planta (Guerra y Aquize 1996: 63). Además de estas características, se puede observar que las casas están agrupadas en terrazas o grupos de ellas; de este modo, se aprovechó el mayor espacio posible, tal como se puede constatar en el mismo lugar. Esto también es posible de notar en el croquis de Guerra y Aquize (1996); si bien no incluye las terrazas en detalle, es posible observar la agrupación de los edificios (Fig. 1, izquierda). Cabe anotar que ambos estudios sugieren que Juscallacta o Uskallacta fue ocupado durante el Intermedio Tardío, lo cual se explica a partir de la ausencia de material inka, además de que no existe, como sí se presenta en Uyu-Uyu, evidencia arquitectónica alguna que dé cuenta de una ocupación foránea.

\subsection{Uyu-Uyu}

Conocido también como «Ullullu», «Uyo-Uyo» y «Yanque Viejo», este asentamiento se encuentra ubicado en el distrito de Yanque, provincia de Caylloma. Se emplaza en una ladera de pendiente suave en la margen derecha del río Colca, circundado por una serie de terrazas de cultivo, al norte del actual pueblo de Yanque, que se encuentra en la margen contraria. El área que ocupa la zona residencial en Uyu Uyu, según Wernke (2003), es de 4,26 hectáreas, en las que se distribuyen 161 estructuras dispuestas en una serie de terrazas, sobre las que se asientan grupos de ellas o residential compounds, que probablemente corresponderían a unidades domésticas individuales o unidades familiares extensas que comparten un área abierta o patio (Fig. 1, derecha).

De estos grupos de estructuras, Wernke nota dos formas de organización. En la primera de ellas, las «casas», tal como las llama Wernke (2009), se encuentran una al lado de la otra ocupando una misma terraza y con sus respectivos accesos abiertos en la misma dirección. En cambio, para el segundo caso, se observan estructuras dispuestas en "L», es decir, que una línea de «casas» es perpendicular a otra y sus accesos confluyen a un mismo espacio abierto; de este modo, abarcan casi la totalidad del espacio en la terraza común. Dado esto, Wernke (loc. cit.) nota, además, luego de una clasificación de las estructuras, tanto por su factura como por su tamańo, que al primer arreglo corresponden las «casas» medianas, mientras que, al segundo, las más grandes y de mejor acabado. Asimismo, señala que existe la ubicación de ciertas edificaciones hacia el centro del sitio, en donde se ubica un espacio abierto tipo plaza, lo que puede significar la mayor preeminencia de estas respecto de las demás. En dicho espacio abierto, se observan dos estructuras que han sido 


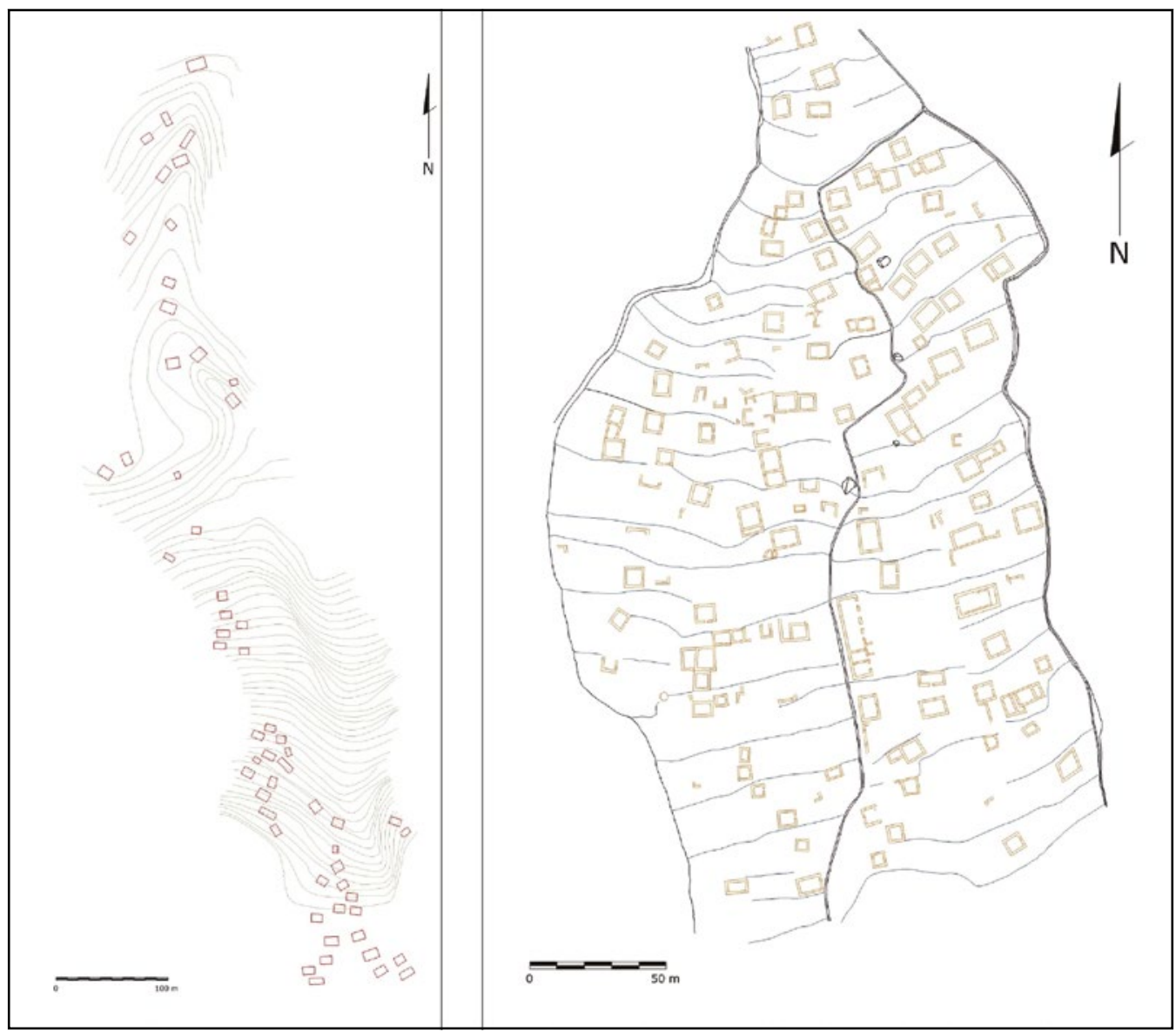

Figura 1. Izquierda: Croquis de Uskallacta, digitalizado de Guerra y Aquize (1996, sin número de figura), en donde se observa cómo se distribuyen los edificios (cuadrados en rojo) de distintos tamaños en grupos definidos por terrazas o grupos de ellas, a lo largo de la ladera. Derecha: Plano general de Uyu-Uyu, redibujado de Wernke (2003: 268, Figura 6.62), en el que pueden observarse los edificios en color naranja y las terrazas de color azul (Elaboración $y$ autoria: Abel Traslavina).

adscritas a dos ocupaciones foráneas: una inka, expresada en una estructura rectangular a la que se ha denominado kallanka, y otra espańola, que correspondería a una capilla colonial.

Además de la ubicación preferencial de ciertas estructuras hacia el centro del asentamiento y alrededor de la plaza, existe un elemento que genera una diferenciación entre las edificaciones. Se trata de un canal, subsidiario del Canal Misme, que cruza todo el sitio de norte a sur, y se ubica a un lado de una calle con la misma trayectoria (Fig. 1, derecha).

De esta manera, Wernke establece para Uyu-Uyu, como se ha mencionado, en primer lugar, una ocupación del Intermedio Tardío, momento en que se constituye como uno de los asentamientos más grandes para el período junto con San Antonio-Chijra (2006: CXXXII). Luego, evidencia una ocupación del Horizonte Tardío, cuyo indicio es la presencia de una kallanka inka; en dicho período, se convertiría en un centro secundario para, luego, ser ocupado durante los primeros años de la presencia hispana, lo que se refleja a través de una capilla colonial asociada a la plaza del edificio inka (Fig. 2).

A partir de las evidencias mencionadas, se colige que nuestro escenario es incompleto y es insuficiente la información que poseemos tanto para permitir una visión a una escala regional desde 


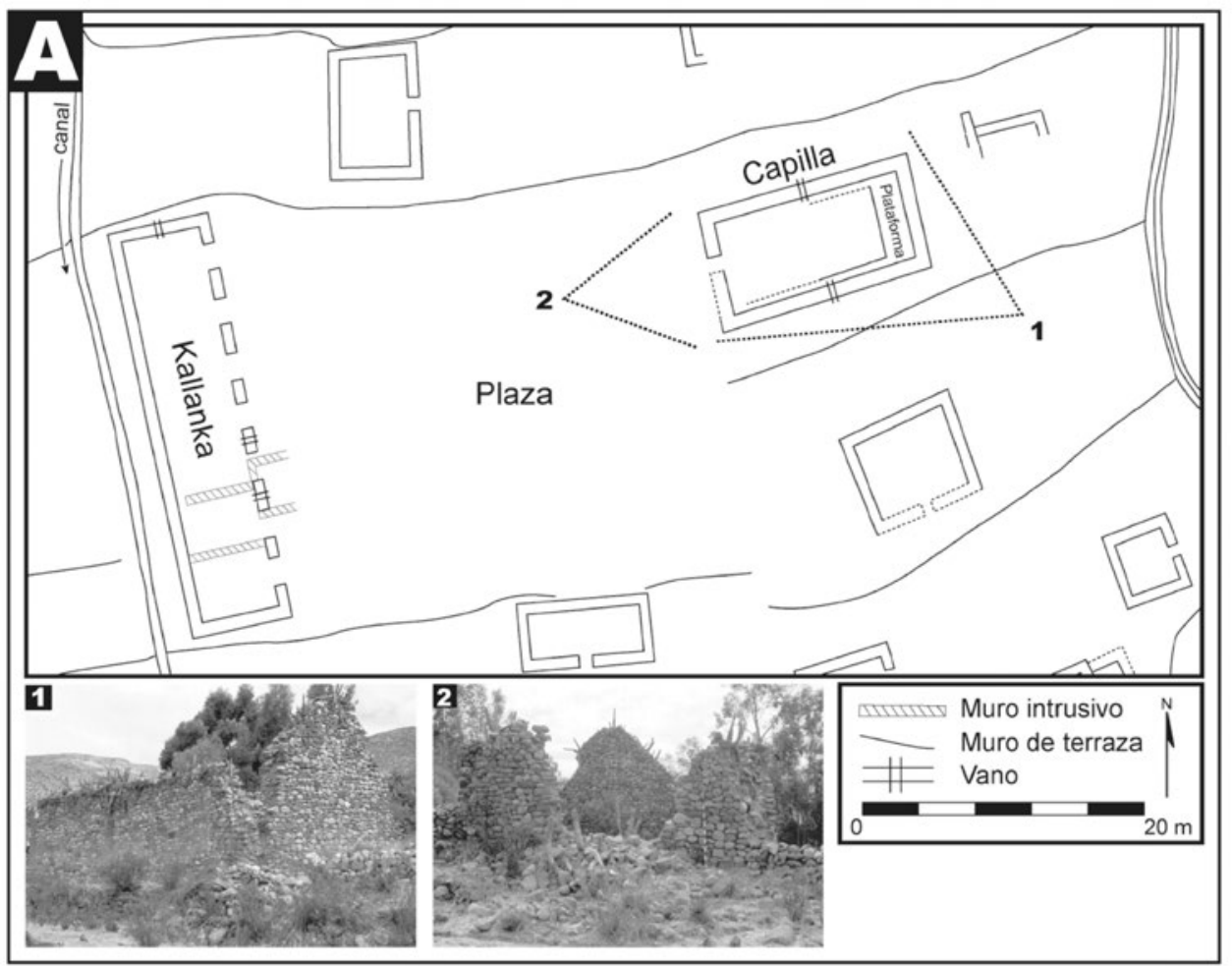

Figura 2. Figura en la que se muestra la evidencia arquitectónica de ocupaciones del Horizonte Tardio (kallanka) y la Colonia (capilla), ubicadas en la zona central del asentamiento de Uyu-Uyu (Traslaviña y Wernke 2014, Figura 3 A).

la arqueología como para plantear un enfoque a una escala más específica desde la etnohistoria. Si bien los estudios desde la arqueología sobre las poblaciones nativas y sus características, para la zona de estudio, cada vez profundizan más en diversos aspectos, tienen mucho por cubrir en cuanto a definir la naturaleza de dichas poblaciones desde lo material. De la misma manera, poco es lo que se puede hacer desde las fuentes documentales para abordar el tema a una escala menor, pues resulta complicado, por ejemplo, tener información relativa a cada poblado en detalle.

Esto se debe a que la manera de abordar la dimensión espacial del problema desde las fuentes documentales tiende a ser más general o incuso tangencial, mientras que, desde la cultura material, se accede a una visión reducida a un asentamiento o incluso a una pequeña porción de este. De ese modo, ambas perspectivas del espacio se encuentran un tanto desconectadas, aunque no del todo divorciadas. Finalmente, como se verá a continuación, es posible profundizar en el estudio del espacio para dilucidar la naturaleza de aquella transformación como producto de la implantación del discurso hispano.

\section{Una perspectiva de la transformación del espacio doméstico y público desde Malata}

En el marco del Proyecto Arqueológico Tuti Antiguo, se llevó a cabo un estudio intensivo del asentamiento denominado Malata entre los años 2006 y 2009 (Wernke y Guerra 2010, Wernke et al. 2012). Malata, ubicado en la margen derecha del río Colca, en los límites del distrito de Tuti, es un asentamiento pequeño que ocupa el fondo de una corta quebrada (Fig. 3, arriba). La mayoría de las evidencias se ubican en el fondo de la mencionada quebrada, en donde se aprecian distintos 
conjuntos arquitectónicos que fueron identificados a partir de sus relaciones físicas expresadas en la convergencia de estructuras y muros, los que daban forma a espacios abiertos de distinto tipo.

A partir de la identificación de los distintos conjuntos arquitectónicos, se establecieron ciertas recurrencias en cuanto a la disposición de los elementos, su distribución y adscripción temporal, como parte del análisis arquitectónico. De esta manera, se pudo identificar los siguientes tipos de contextos domésticos y públicos.

\subsection{Definiendo la esfera de lo doméstico en Malata}

Luego del análisis de las relaciones físicas entre las variables identificadas (estructuras, muros y espacios abiertos), se reconocieron grupos arquitectónicos a partir de los que se definieron tipos de contextos domésticos. En este punto, si bien es necesario ser prudente en cuanto a las definiciones que se utilicen, considero sensato llamar la atención sobre aquellos términos bajo los que se conceptualiza la esfera de lo doméstico, pues podrían llevarnos a serios problemas. Si bien se han utilizado términos como "grupo patio» o «unidad alveolar» para hacer referencia a los conjuntos de edificios, se utilizan los términos «casa» o «vivienda» para aludir a cada uno de ellos, como lo han hecho para estudios similares Matos Mendieta (1972), Bonnier (1997) y DeMarrais (2002) en la sierra central del Perú. Dicho término ha sido usado en el sentido occidental para referirse a un «edificio de una o pocas plantas destinado a vivienda unifamiliar, en oposición a piso» ${ }^{1}$, lo que claramente pretende ir un poco más allá de tan neutrales conceptos como "esfera de lo doméstico» o «espacio doméstico», pero sin usar datos que lo sustenten. Al respecto, Nash señala que «Una casa representa diferentes conceptos de diferentes grupos de personas. Las actividades que se llevan a cabo dentro de la estructura de la casa están definidas por la idea de casa de un grupo social (Rapoport 1990). Debido a que es imposible entender el concepto de casa wari o de cualquier grupo dentro del Horizonte Medio Andino, el significado de la casa, así como los elementos que la componen no pueden ser asumidos (Moore 1996)» (2002: 53). Entonces ¿cuál es la expresión material de "casa» para el caso que nos ocupa?

Al respecto, Vokral afirma que, en el caso altiplánico:

Según Carter y Mamani (1982:237-242) inmediatamente después del matrimonio religioso se realiza en Irpa Chico la construcción de la casa [...] [que] es el último paso del ritual matrimonial. En Huichay Jaran el matrimonio religioso no está vinculado con la construcción de la casa. La construcción empieza más o menos un año después de haber empezado la vida en común, cuando generalmente el primer niño está en camino o ha nacido ya. La casa del nuevo matrimonio se construye dentro de los límites de la tenencia familiar, cerca de la casa paterna de uno de los cónyuges, es decir, es un tipo de residencia tanto uxorilocal como virilocal. Aunque la pareja migre, se construye una casa de su propiedad localmente. En dicho caso las habitaciones son utilizadas por otros miembros familiares, pero se consideran como propiedad de los ausentes [...] La casa consta en primer lugar de dos habitaciones independientes: la cocina y una habitación en la que guardan cosas y donde también se puede dormir. [...] Poco a poco se construyen más piezas si la necesidad lo requiere y si se dispone de dinero (1991: 137).

De acuerdo con el texto anterior, la casa representa la emergencia de una nueva familia, con sus respectivas particularidades, y se construye dentro de terrenos que ya corresponden a una familia anterior, es decir, que pertenecen a la familia de uno de los cónyuges. Este aspecto se evidencia incluso en la adscripción simbólica que tiene el surgimiento de los poblados como expresión familiar en el valle del Colca, como en el caso de Yanque, sobre el cual, en el contexto del establecimiento de las reducciones toledanas, se narra el traslado del antiguo pueblo al nuevo como expresión del intercambio entre dos familias influyentes y amigas: los Choquehuanca y los Checa (Pease 1977: 167-168). Se procede a la construcción de la casa por habitaciones independientes, al menos, una para cocina y otra usada como depósito; sin embargo, ambas pueden ser utilizadas también como lugares para dormir. En otras palabras, si bien cada habitación puede cumplir más de una función a la vez, no deja de ser independiente, y es posible construir más habitaciones de ser necesario. Por todo esto, la idea de casa en las zonas rurales difiere de aquella otra concepción occidental de casa, 

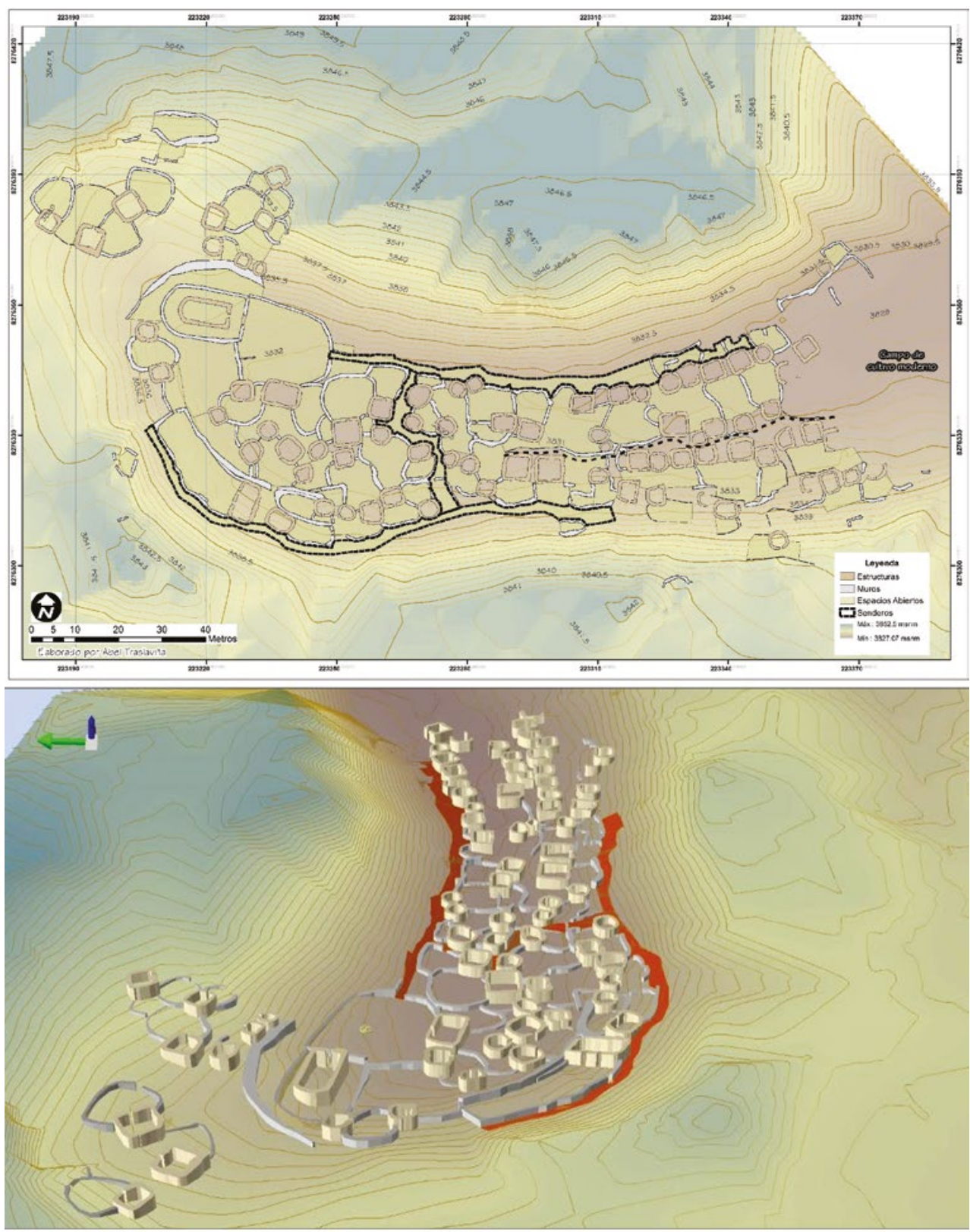

Figura 3. Arriba: Vista general en planta de Malata señalando los elementos identificados: estructuras, muros y espacios abiertos, así como los senderos. Abajo: Vista general idealizada de los espacios públicos hispano e inka. Nótese cómo se relacionan los senderos con cada uno de los espacios públicos en la zona oeste: el inka dando la espalda a los edificios del fondo de la quebrada, y el hispano dándoles frente. La flecha verde indica el norte (Elaboración y autoría: Abel Traslaviña, a partir de información del Proyecto Arqueológico Tuti Antiguo).

descrita anteriormente. Por ello, se plantea aquí que, para el caso de los Andes, la casa fue pensada, a grandes rasgos, como un amplio espacio (aquel designado desde un inicio dentro de un terreno familiar afín y precedente) que albergaba un conjunto de habitaciones independientes, cada una de las cuales podía responder a múltiples actividades. 


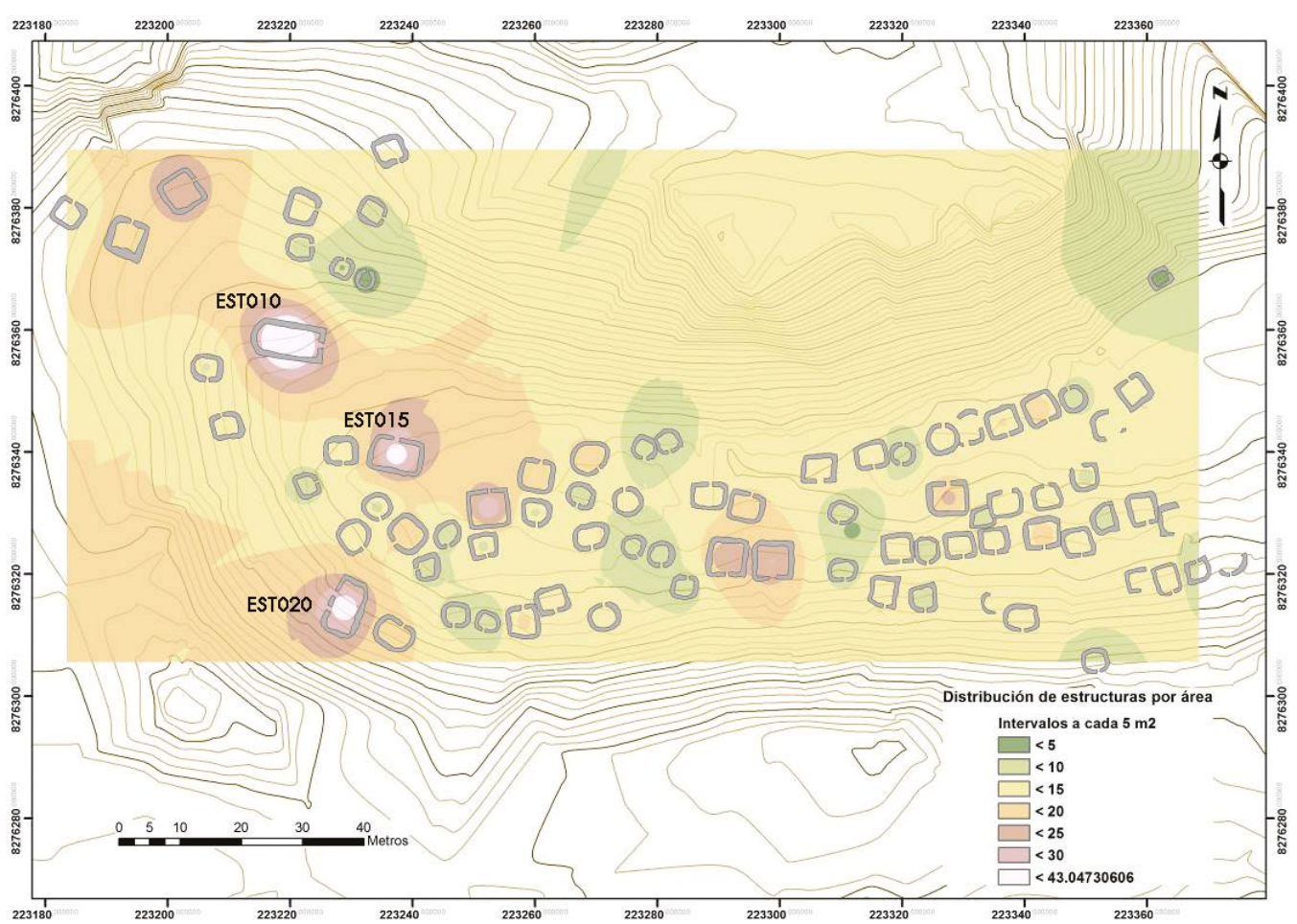

Figura 4. Mapa de densidad de estructuras según sus áreas internas. Nótese la gran variabilidad de valores de área interna por estructura en el asentamiento. Asimismo, la forma en planta de ESTO2O y ESTO1O no son usuales en el asentamiento (Elaboración y autoría: Abel Traslaviña, a partir de información del Proyecto Arqueológico Tuti Antiguo).

De esta manera, al pensar en la casa como un conjunto de habitaciones o edificios menores, es posible, además, plantear una correspondencia con aquellos conjuntos de edificios identificados durante el análisis de Malata. En esa línea, la casa no sería un edificio, sino un grupo de edificios que ocupan un terreno familiar, ubicados en torno a un espacio abierto común. Cada uno de estos edificios estaría albergando distintas actividades, razón por la cual difieren en su área interna (Fig. 4). Asimismo, la cantidad de edificios que conforman la casa respondería, por ejemplo, al crecimiento de la familia y/o al desarrollo de nuevas actividades en el tiempo. Este concepto se condice con cómo se constituye, como se verá a continuación, la "Casa» tipo 4, lo que es coherente con representar a la ocupación original del asentamiento (Fig. 6).

Dicho esto, los tipos de "casas» identificados son los siguientes:

- «Casa» tipo 1: Es una casa rural de influencia hispana. Si bien es simple, demuestra cierto grado de importancia frente a los otros tipos de casa debido a la presencia de un muro elevado que define su espacio abierto o patio, a la vez que restringe su acceso y reduce su visibilidad desde el exterior. Su ubicación se da alrededor de la zona de influencia pública hacia el extremo noroeste del asentamiento. Este tipo de casa habría albergado a algún tipo de funcionario político o religioso bajo el régimen peninsular; esto se evidencia en el único fragmento de cerámica vidriada en todo el asentamiento encontrado en su interior (Fig. 5, arriba y Fig. 6, arriba).

- «Casa» tipo 2: Es una casa rural de influencia hispana, pero con elementos locales. Expresa su importancia tanto en la ubicación preferencial, muy próxima a la zona de influencia pública, como en su constitución jerárquica, expresada en la factura diferencial de sus edificios, en donde el más importante - - , por ende, el más restringido- es el mejor elaborado. Si bien se emparenta con el tipo de casa anterior, esta habría albergado a una persona o grupo de personas importantes provenientes del grupo local, posiblemente algún curaca. 


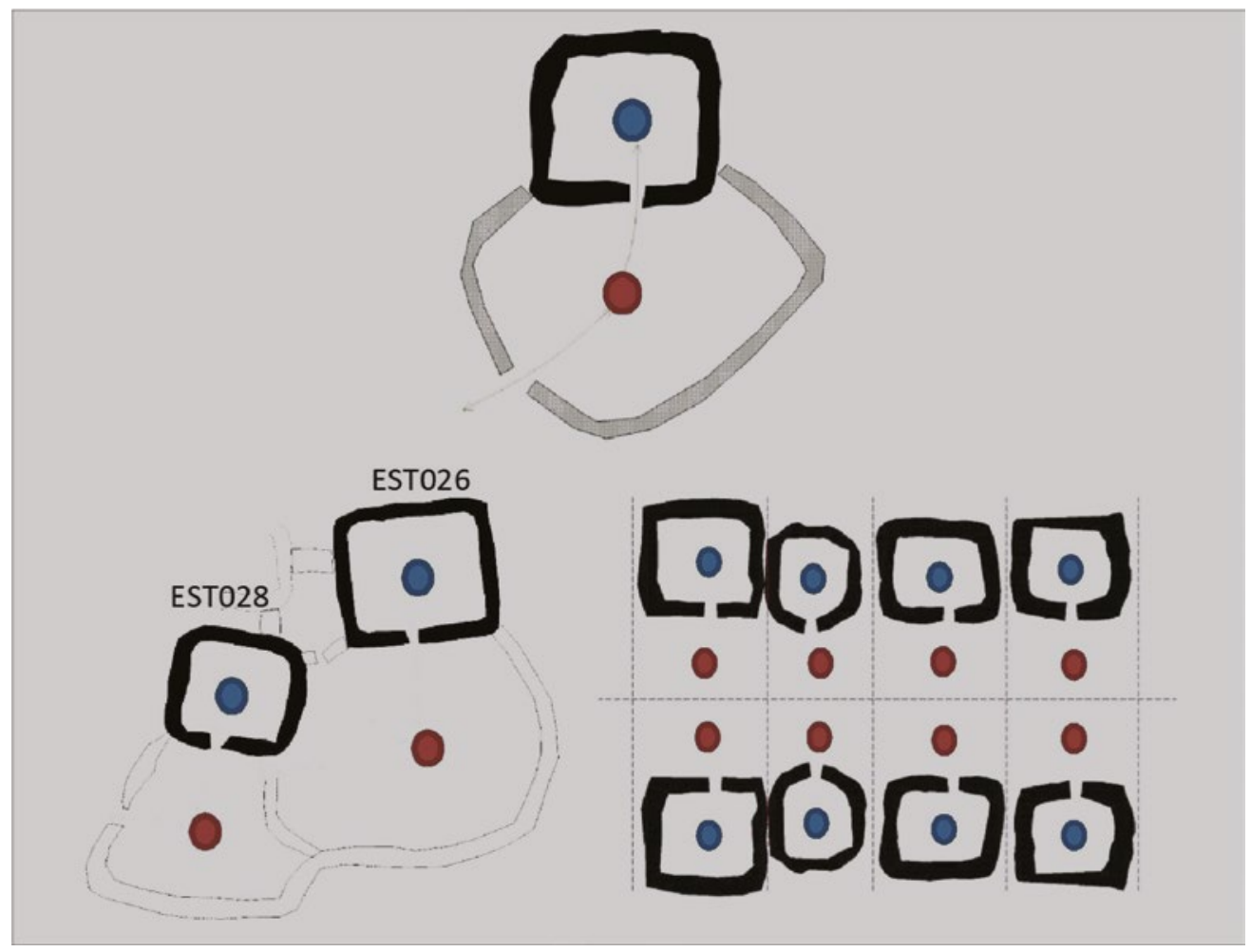

Figura 5. Esquema de las distintas expresiones de casa que corresponderian a la influencia hispana en el sitio de Malata: Arriba, la Casa Tipo 1. Abajo a la izquierda, una Casa Tipo 2. Abajo a la derecha, un grupo que representa la idea de Casa Tipo 3 (Elaboración y autoría: Abel Traslavina, a partir de información del Proyecto Arqueológico Tuti Antiguo).

Esto se basa en el hallazgo de finos artefactos en el interior de ambos edificios (Fig. 5, abajo a la izquierda y Fig. 6, abajo izquierda y derecha).

- "Casa» tipo 3: Es una casa rural de influencia hispana con elementos locales, pero de menor jerarquía. Se trata de un grupo de casas dispuestas en línea, que se componen de un edificio con un espacio abierto común. Cada uno de estos edificios no habría funcionado necesariamente como casas, pero, al parecer, fueron establecidos de esa manera para agrupar familias bajo la lógica de la congregación de población y su reasentamiento. Este arreglo es de menor jerarquía, debido a que, a diferencia de los anteriores, no cuenta para sí con un espacio abierto por completo, sino que lo comparte con las casas contiguas. Estos edificios habrían albergado a personas dedicadas a algún tipo de actividad productiva, como el trabajo con textiles, metales, etc. (Wernke y Guerra 2010) (Fig. 5, abajo a la derecha).

- «Casa» tipo 4: Es una casa rural de naturaleza local. Se trata de un grupo de edificios no tan elaborados y que se disponen alrededor de un espacio abierto. Cada uno de estos edificios correspondería a funciones distintas llevadas a cabo a la vez, o en el transcurrir del tiempo, lo que se evidenciaría en la variabilidad existente entre sus áreas internas, así como en el número de edificios que la componen (Fig. 7).

\subsection{Definiendo la esfera de lo público en Malata}

- Espacio Público tipo 1: Está compuesto por un edificio simple de forma rectangular y con dos accesos en uno de sus lados alargados (EST020), los cuales desembocan en un espacio abierto alargado, delimitado por muros con dos accesos: uno por el sur y el otro por el noroeste (Fig. 8, arriba). 


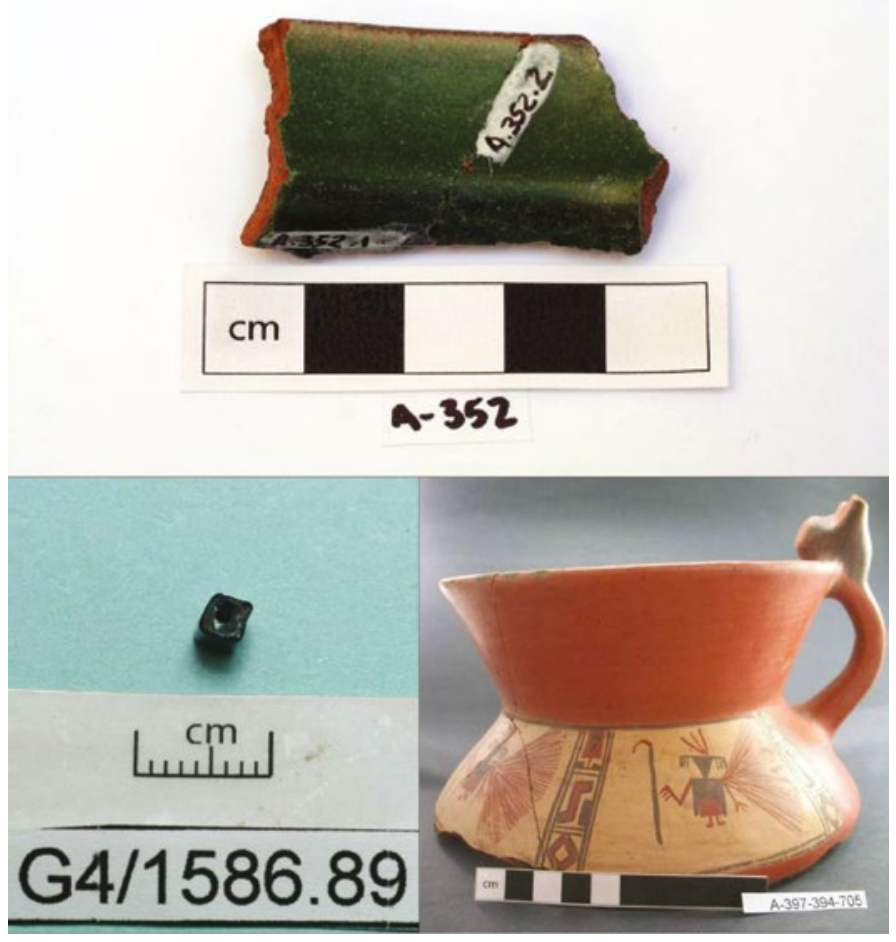

Figura 6. Arriba: Fragmento de cerámica vidriada de color verde ("Casa" Tipo 1). Abajo, izquierda: vasija hallada al interior de EST028. Abajo, derecha: cuenta de vidrio hallada al interior de EST026 ("Casa" Tipo 2) (Reproducción con permiso del Proyecto Arqueológico Tuti Antiguo).

- Espacio Público tipo 2: Se trata de un arreglo que incluye dos edificios asociados a un espacio abierto común. El primero de ellos (EST010) es de forma rectangular y presenta un acceso en uno de sus lados cortos; este edificio se inscribe en una plataforma y posee dos juegos de escalones que solucionan el desnivel entre su acceso y la superficie del espacio abierto. El segundo de los edificios (EST015) es de forma rectangular con el acceso en uno de sus lados largos y se comunica directamente con el espacio abierto. Además, existe una plataforma de líneas de piedras concéntricas ubicada hacia el centro del espacio abierto (Fig. 8, abajo).

Los tipos expuestos en este apartado resaltan, porque (i) se encuentran edificios con formas inusuales dentro del asentamiento (EST020 y EST010), (ii) sus edificios poseen las mayores medidas de superficie para sus áreas internas en comparación con los demás edificios del asentamiento (Fig. 4) y (iii) se ubican hacia el extremo oeste, zona que permite una mejor visibilidad del núcleo del asentamiento, ubicado en el fondo de la quebrada (Fig. 3, arriba y Fig. 4).

Estos conjuntos arquitectónicos, Espacios Públicos tipo 1 y 2, no coinciden ni en su arreglo ni en las características de sus edificios y espacios abiertos asociados con ninguno de los tipos correspondientes al espacio doméstico, lo que está apoyado en la identificación de los edificios EST010 como una capilla colonial y EST020 como una kallanka inka. Por ello, sus espacios abiertos asociados corresponderían a plazas y no a patios, que se definen por la correspondencia de cada uno de ellos a (i) una ocupación foránea pero distinta en el tiempo y (ii) disímiles funciones. La primera característica se infiere directamente, pero ¿qué hay de la función que cumple cada espacio, si bien ambos pueden tipificarse, a grandes rasgos, como públicos? 


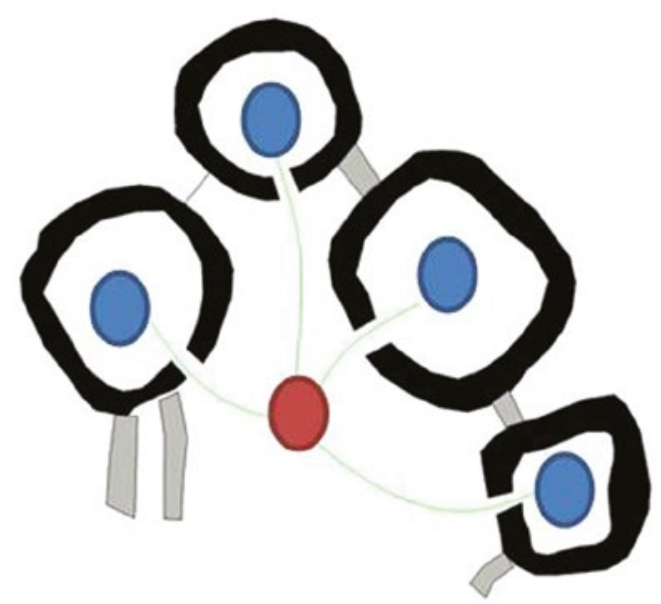

Figura 7. Esquema de una Casa Tipo 4. Nótense los distintos tamaños de edificios que la componen y cómo los edificios se relacionan entre si mediante el espacio abierto en común (Elaboración y autoría de Abel Traslaviña, en base a información del Proyecto Arqueológico Tuti Antiguo).

Como se señala en la información proveniente de las excavaciones (Wernke y Guerra 2010), la EST010 o capilla habría tenido un desarrollo particular. En un primer momento, se presentaba sola y directamente ubicada sobre el fondo de la quebrada, con un desnivel que se solucionó mediante un juego de cuatro peldaños. Posteriormente, se construyó una plataforma alrededor de ella, cubrieron dos de los peldaños originales y se construyó un nuevo juego de cuatro peldaños, además de que se estableció o formalizó la plaza, en la que se ubicó en medio una cruz y un edificio asociado hacia el sur (Wernke et al. 2012; Traslavińa y Wernke 2014).

Esta «transformación» en torno a la capilla coincide con la aparición del nuevo grupo de casas, correspondientes a la "Casa» tipo 3, ubicada hacia el extremo este del asentamiento, que se comunica con la plaza a través de un sendero ubicado hacia el extremo norte, al pie del cerro que delimita la quebrada en esa zona (Fig. 3, abajo). Es decir, aquellas personas en algún momento tendrían que haberse comunicado con el Espacio Público tipo 2, tipificado como espacio público hispano, a donde llegarían como parte de un breve recorrido, lo que evoca el tránsito efectuado a los lugares sacros cristianos a la manera de una procesión. Dicho de otra manera, el hecho de que la plaza de la capilla sea el espacio abierto con mayor valor de superficie (324,15 metros cuadrados) se debe posiblemente a la intención de congregar a todas aquellas nuevas personas que llegaron al asentamiento, puesto que, para las actividades eclesiásticas, el interior de la capilla no se habría dado abasto. Por tal razón, este aspecto podría tipificar al espacio público hispano como uno cuya función preeminentemente habría sido la de congregar a la población para impartir la doctrina cristiana (Fig. 9).

De otro lado, el Espacio Público tipo 2, correspondiente al espacio público inka, si bien cuenta con una amplia plaza de naturaleza convocante, no habría podido contener a toda la población original en el asentamiento, como sí se buscó lograr con el espacio público hispano (Fig. 8, arriba). Ambos espacios públicos se ubican hacia el extremo oeste (que coincide con el origen de la quebrada, y por lo cual se encuentra en una zona más elevada y con mayor dominio visual); la relación que establecieron cada cual en su momento con los distintos espacios domésticos en el asentamiento fue distinta (Fig. 3, abajo). En el caso del espacio público inka, es posible notar que la kallanka no se encuentra con los vanos orientados hacia donde se habría ubicado la población original —en el fondo de la quebrada-, sino que da la espalda a la gran mayoría de las estructuras. La kallanka se encuentra sobre una superficie elevada producto de la construcción precedente de la terraza agrícola sobre la que yace (Williams 2009). Su plaza se formaliza a partir de muros que la delimitan, y que establecen dos accesos, pero este proceso no habría comprometido el trazo original del asentamiento; esto quiere decir que la ocupación inka adapta su presencia a la configuración ya existente. De esta manera, tal y como está 


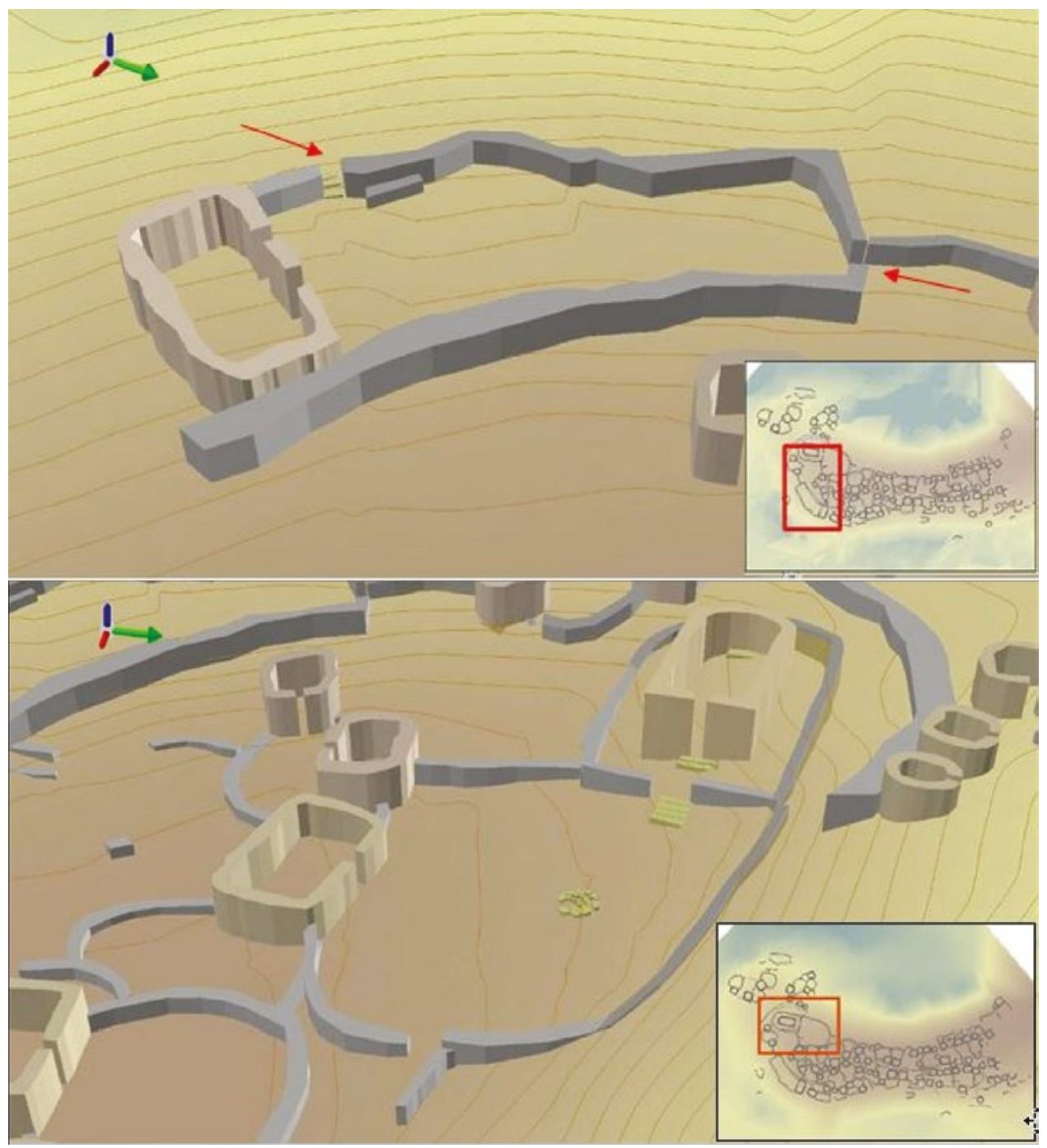

Figura 8. Arriba: Kallanka y su plaza. Nótense los dos accesos al espacio abierto, señalados por flechas rojas. Abajo: Capilla, edificios asociados y plaza. Nótense los distintos tamaños de edificios que la componen y cómo los edificios se relacionan entre si mediante el espacio abierto en común. La flecha verde indica el norte Elaboración y autoría de Abel Traslaviña, en base a información del Proyecto Arqueológico Tuti Antiguo).

constituido el espacio público inka en el caso de Malata, no habría buscado reunir a toda la población presente en el asentamiento; más bien, dosificaba la presencia de personas en su plaza privilegiando la concentración de actividades más que de personas (Fig. 8, arriba).

En el caso del espacio público hispano, la comunicación con respecto a los distintos espacios domésticos, a diferencia del espacio público inka, sí es directa, debido a que el sendero norte desemboca en la plaza y el acceso de la capilla es visible al llegar a esta (Fig. 3, abajo). De esta manera, la plaza, tal y como está dispuesta, sí habría convocado a la población para congregarse en ella, con lo cual reforzaba la apariencia significativa de este lugar mediante los muros que la delimitan y la presencia de una cruz, que pudo ser vista a medida que se aproximaban a la plaza, tal como habría sucedido con la capilla y el contraste generado con la construcción de la terraza en torno a ella (Fig. 9). Esta interacción se desarrolla en términos temporales a continuación. 


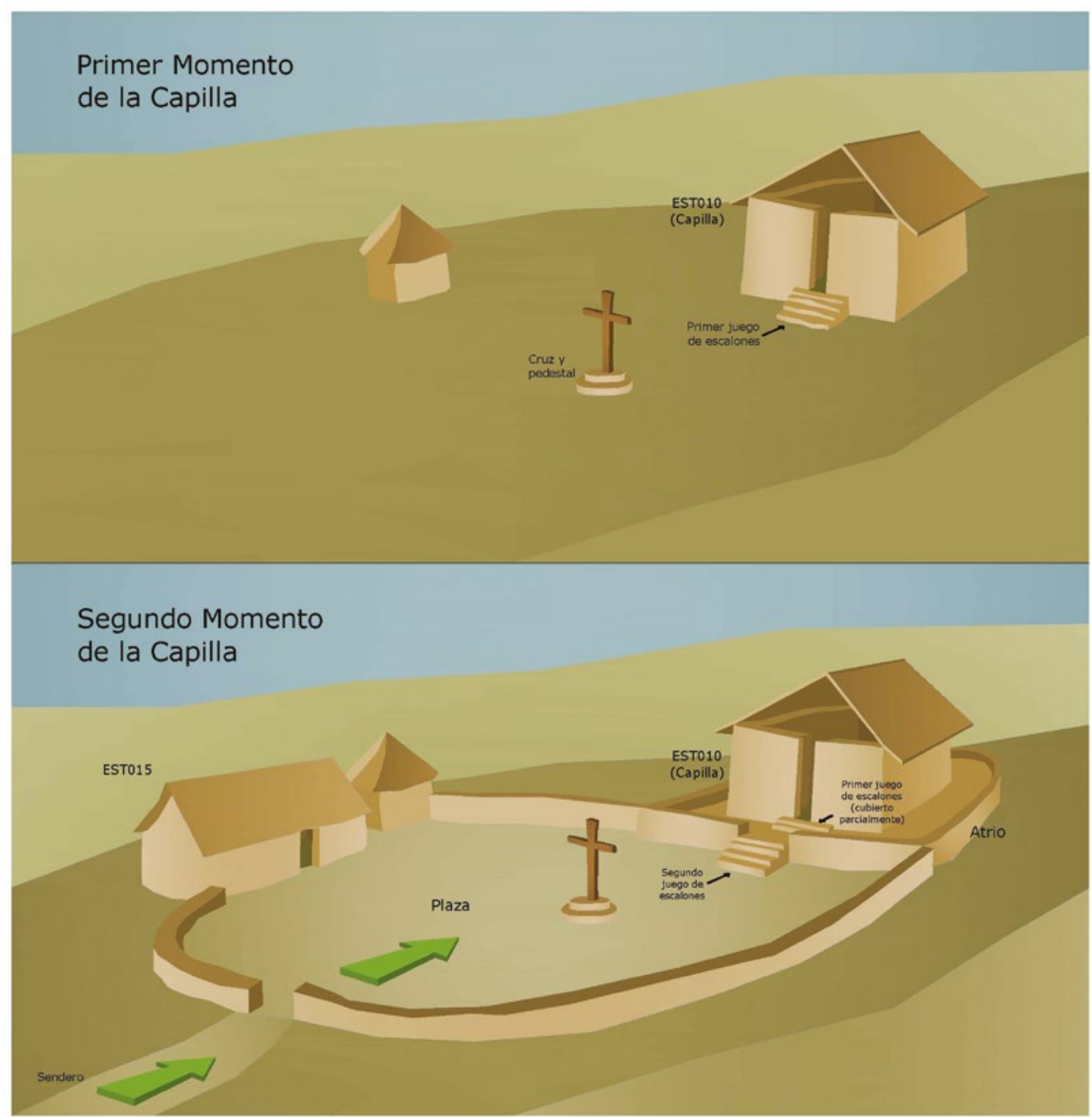

Figura 9. Vista general idealizada del espacio público hispano. Arriba, el primer momento de la Capilla en donde se observa sólo a la capilla en su relación directa con el piso de la quebrada. Abajo, la modificación de la Capilla, la formalización del espacio de congregación (plaza), la adición de un segundo edificio asociado (ESTO15) y el sendero que direcciona el flujo de los nuevos pobladores de la zona este (Elaboración y autoría de Abel Traslaviña, en base a información del Proyecto Arqueológico Tuti Antiguo).

\section{Malata a través del tiempo}

Luego de definidos los contextos que componen el asentamiento, se insertan en el eje temporal para mostrar su crecimiento y cómo se suceden las transformaciones a través del tiempo.

\subsection{Fase 1}

Correspondería a la ocupación original del asentamiento, que habría estado concentrada en el fondo de la quebrada, y constaría de grupos de edificios de tendencia circular o cuadrangular con esquinas redondeadas en su vista en planta, además de la presencia de una terraza agrícola hacia el oeste del asentamiento. La evidencia proviene de «Casas» tipo 4 incompletas debido a la modificación realizada posteriormente en esa zona (Fig.10, arriba). 


\subsection{Fase 2}

Corresponde a la primera ocupación foránea en Malata, evidenciada por la presencia de la kallanka inka (EST020), para lo cual se reutiliza una terraza agrícola (Williams 2009). Su presencia no habría vulnerado la configuración original y se focalizó hacia la zona oeste del asentamiento, canalizando los flujos a través de un sendero ubicado hacia el sur (Fig. 3, arriba y abajo, y Fig.10, abajo).

\subsection{Fase 3}

Se trata de la segunda ocupación foránea en Malata, representada por la presencia hispana. A continuación, se presenta la subdivisión de esta fase.

\subsubsection{Subfase 3a}

Corresponde al inicio de la ocupación hispana en Malata. Presenta un edificio religioso o capilla (EST010) hacia la zona oeste del asentamiento, que ocupa un área libre de construcciones (Fig. 11, arriba). Su ubicación habría aprovechado la mayor elevación y dominio visual, además de ubicarse frente a las «Casas» tipo 4, que ocupaban el fondo de la quebrada (Fig. 7 y Fig. 3, arriba y abajo).

$\mathrm{Al}$ inicio de la ocupación hispana — durante la subfase 3a-, la capilla fue construida de manera provisional por los religiosos — posiblemente franciscanos-, que llegaron al valle del Colca alrededor de 1540, al haberse instalado la encomienda de Gonzalo Pizarro (Heras 1992: 159). La presencia de esta capilla correspondería al proceso que Meiklejohn (1988: 249) ha denominado «cristianización», que para este caso puede ser entendida como una primera aproximación a los nativos de parte de los religiosos, proceso que se materializó desde su construcción misma. Este primer acercamiento de la doctrina cristiana a los nativos de Malata se habría traducido en actividades específicas, como su bautizo, y, con ello, — muy probablemente- un primer registro sobre su constitución inicial como grupo, expresado quizás en documentación como «censos», «visitas» o como mínimo en "padrones de feligreses».

\subsubsection{Subfase $3 b$}

Es consecuencia de la subfase anterior. Se construye un grupo de «Casas» tipo 1 en el extremo oeste del asentamiento, que habrían tenido relación directa con las actividades en torno a la capilla por su cercanía, aun cuando sus accesos no estuvieron orientados hacia ella (Fig.11, abajo). En este caso, tampoco se hacen mayores modificaciones en el asentamiento.

Posiblemente, la instalación progresiva de un religioso, con la primera aparición de las "Casas» tipo 1 al extremo noroeste del asentamiento durante esta subfase, se habría dado como parte de una programación de actividades un tanto más permanentes con miras a que Malata sea parte de lo que se conocía como una doctrina. Esta programática se relacionaría a su vez con el inicio del proceso de «evangelización», pues implicaría a la larga «un proceso mediante el cual uno no-creyente, o bien un creyente que ha sido bautizado, queda empapado del significado y los valores del evangelio cristiano. De esta manera, mientras que la cristianización es entendida como un fenómeno sociocultural, la palabra evangelización connota una comprensión de lo que significa ser cristiano y, en consecuencia, la persona evangelizada brinda su adhesión a Cristo. De ser un no cristiano pasa a convertirse en discípulo de Cristo» (ibid.: 249-250).

De esta manera, la subfase 3 b estaría relacionada con afianzar el proceso de "cristianización", para lo cual, en el transcurso de cinco a 10 años de establecida la capilla, se habría instalado de manera más permanente algún religioso, posiblemente un franciscano. Así, estando los religiosos ya enterados a estas alturas de ciertas particularidades de la población, pudieron programar actividades con la intención de que los nativos interioricen la doctrina cristiana, razón por la que se construye el grupo de «Casas» tipo 1 en la zona noroeste de Malata, lo que dará pie posteriormente al proceso de evangelización. 


\subsubsection{Subfase 3c}

Corresponde a la formalización del proceso de evangelización, que se habría llevado a cabo durante la década de 1550; Malata estuvo bajo este régimen hasta entrada la década de 1570 (Fig.12, arriba y abajo). Este proceso se puede describir en tres eventos. Una vez que los religiosos franciscanos decidieron tener una presencia más constante en Malata, se procedió a delinear las actividades correspondientes al proceso de evangelización. Para ello, ya no era suficiente contar con la capilla como tal, debido a que era necesario transformar la capilla para evidenciar ese nuevo proceso. Por esta razón, para otorgarle ese sentido "excelso» a la conversión de los nativos en discípulos de Cristo, se construyó una plataforma alrededor de la capilla, a la manera de un atrio, que cubría dos escalones del primer juego de cuatro para, luego, construir un nuevo juego de cuatro escalones que comunicaban la capilla hacia la nueva plaza, en la cual se construyó una peana que habría soportado una cruz, posiblemente de madera (Fig. 9).

Después de la modificación de la capilla, se procedió a definir la plaza, y se añadió un nuevo grupo de "Casas» tipo 1 ubicadas al norte de la capilla, además de estructuras menores, ubicadas sobre una nueva terraza. La presencia de estas casas, además de las estructuras menores (que habrían servido de depósito), estaría relacionada con un edificio nuevo asociado a la plaza (EST015). Este edificio habría cumplido funciones de tipo político-administrativo, como lo muestran las excavaciones; posiblemente, habría estado relacionado con la solución de conflictos entre pobladores o la administración del trabajo. A la par de la construcción de estas nuevas casas y el edificio público, se procedió al desmontaje de edificios de la ocupación original ubicados hacia el este del asentamiento (Fig. 9).

Finalmente, luego del desmontaje de los edificios de la ocupación original de Malata, ubicados hacia el este, se procedió a la construcción de grupos de "Casas» tipo 3, así como la «Casa» tipo 2, muy próxima a la plaza. Se delimitó un sendero al norte con la ayuda de los muros de las nuevas casas para conducir los flujos desde ellas hacia la plaza. Se construyó también un pasaje para la comunicación transversal en el asentamiento. Es necesario señalar el carácter único de la "Casa» tipo 2, que se encuentra muy próxima a la plaza, y se sitúa en la intersección entre el sendero norte y el pasaje transversal (Fig. 3, arriba y abajo, y Fig.13).

\section{Ideas finales}

La transformación ocurrida en Malata, como se ha mencionado, no tiene par en ninguno de los asentamientos de la parte alta del valle del Colca. Esto hace de Malata un caso muy particular, en donde el desarrollo de la esfera de lo religioso y político — expresado en los edificios asociados a la plaza hispana y su consecuente formalización como espacio político y para el culto- afecta la esfera de lo doméstico.

Como se pone en evidencia en los casos apoyados en información documental, al plantearse una modificación del espacio desde la esfera de lo público, necesariamente se verá modificado el trazo original para ajustarlo al nuevo orden. Este «ajuste» ocurre en buena medida debido a la presencia de los senderos, que evocan las calles en las posteriormente institucionalizadas reducciones toledanas. Éstos sugieren el tránsito desde la zona doméstica hacia un amplio espacio de encuentro como la plaza de la capilla en Malata, que se construye posteriormente (Fig. 3, arriba y abajo). Todo ello implica no solo que el orden general original fue acondicionado al nuevo discurso que rige la organización del asentamiento, sino que, además, cada unidad doméstica se habría acondicionado — por decirlo de alguna manera - para ajustarse a los nuevos flujos de tránsito, así como para establecer cierta jerarquía en la esfera doméstica relativa a su proximidad al espacio público. Esto se evidencia al comparar la «Casa» tipo 2, que establece una jerarquía de espacios y de habitantes dentro del mismo conjunto, con la "Casa» tipo 3, que muestra mayor uniformidad de conjunto y que habría albergado a distintos grupos de personas de similar estatus. 

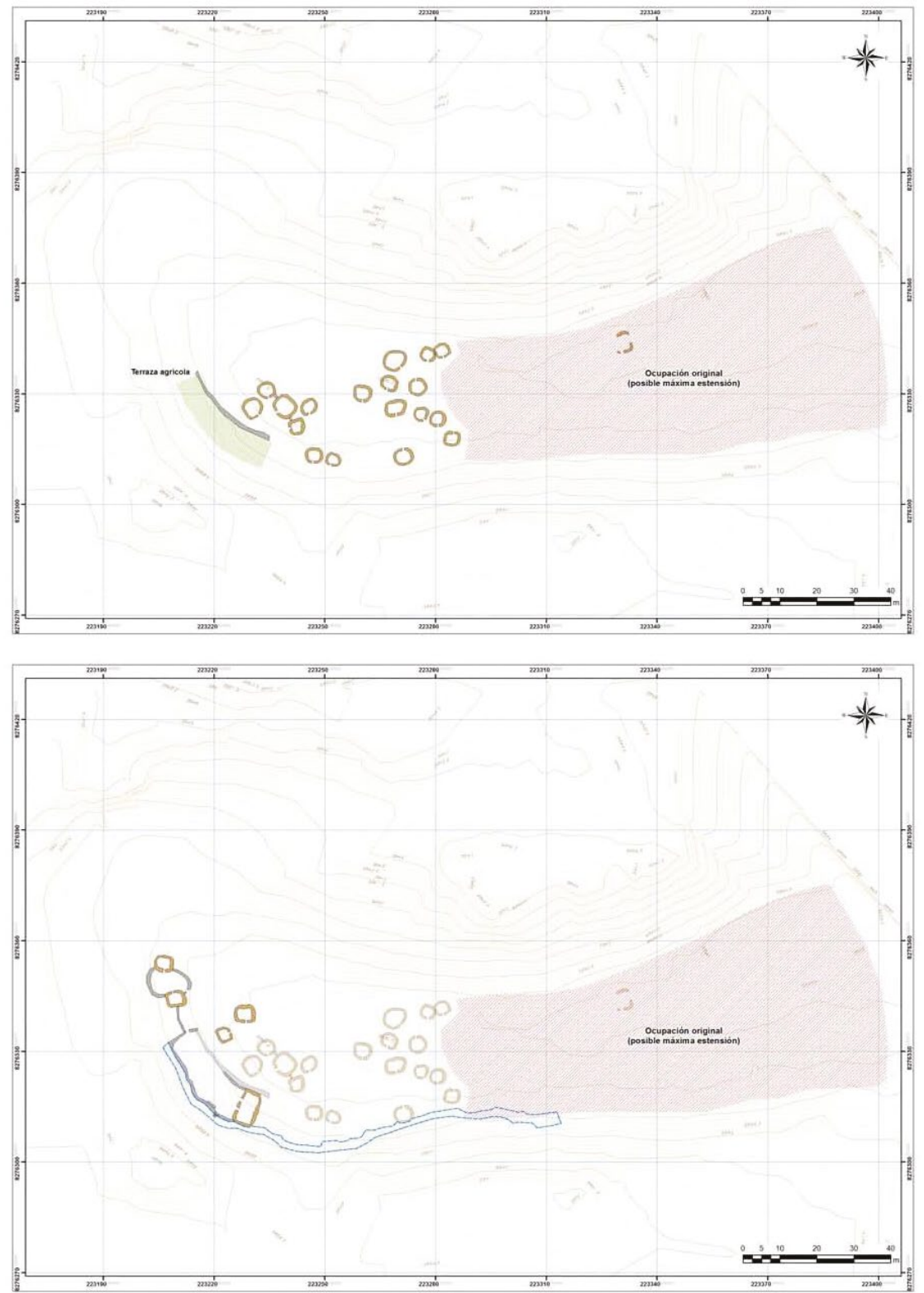

Figura 10. Arriba: Vista general del asentamiento durante la Fase 1 de ocupación. El área señalada hacia el este representa la posible zona de extensión de la ocupación original del asentamiento, mientras que aquella hacia el oeste representa la terraza agrícola. Nótese que el grupo de edificios correspondería a "Casas" Tipo 4, incompletas por posteriores modificaciones en esa zona. Vista general del asentamiento durante la Fase 2 de ocupación, que se concentró hacia la zona oeste. Nótese la presencia de edificios por pares que habrían guardado algún tipo de relación con el espacio público inka, pero que no han sido definidos por carecer de información. La zona delineada en azul corresponde al sendero por el que se podía acceder a la kallanka. Abajo: Vista general del asentamiento durante la Fase 2 de ocupación, que se concentró hacia la zona oeste. Nótese la presencia de edificios por pares que habrían guardado algún tipo de relación con el espacio público inka, pero que no ban sido definidos por carecer de información. La zona delineada en azul corresponde al sendero por el que se podía acceder a la kallanka (Elaboración y autoría de Abel Traslavina, en base a información del Proyecto Arqueológico Tuti Antiguo). 

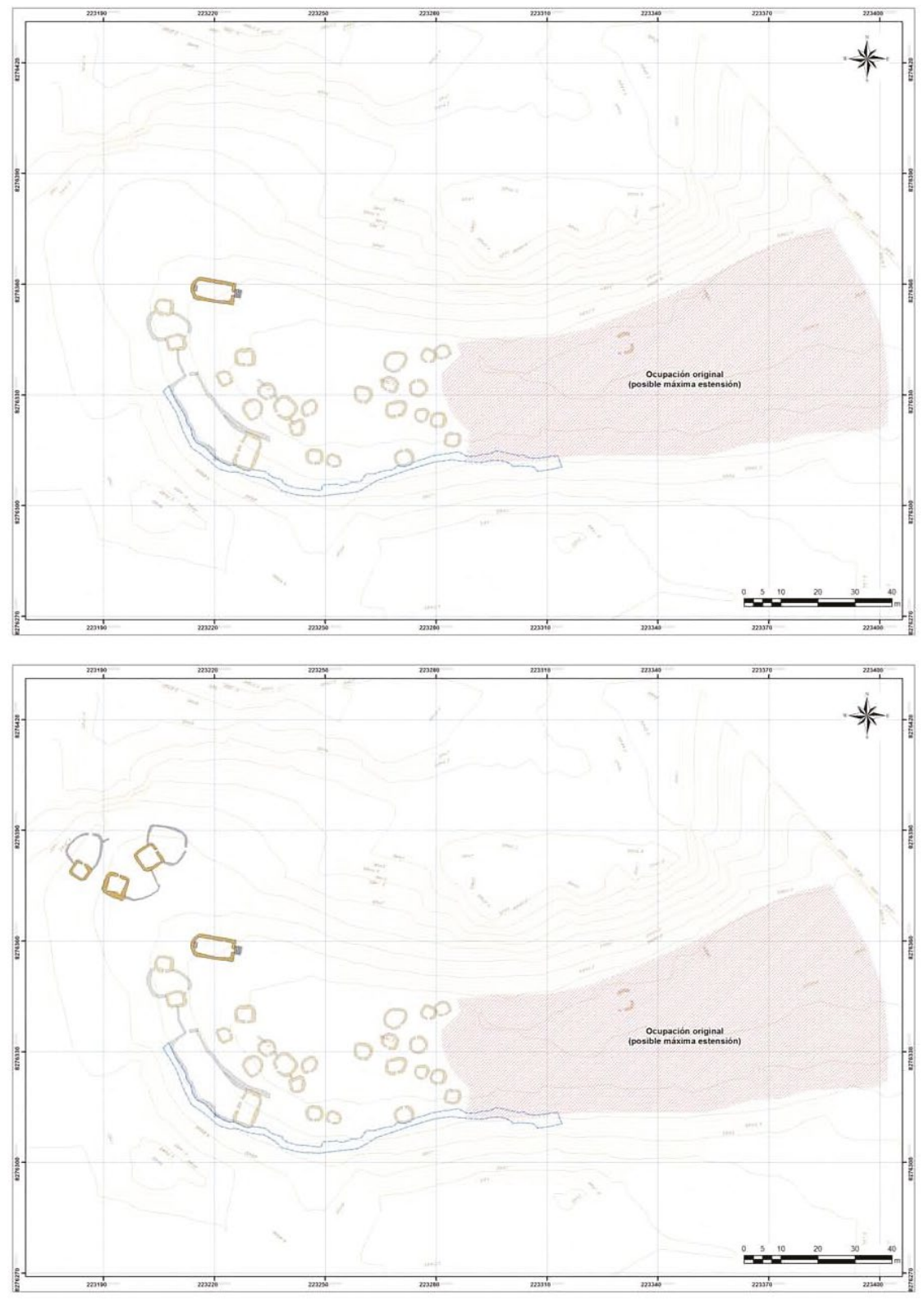

Figura 11. Arriba: Vista general del asentamiento durante la Sub-Fase $3 a$ de ocupación, que se focalizó hacia el oeste. Nótese que la capilla se ubica en un punto elevado con respecto a los demás edificios en el fondo de la quebrada, orientándose su frontis hacia dicha zona. Abajo: Vista general del asentamiento durante la Sub-Fase 3 b de ocupación. El grupo de "Casas" Tipo 1 se ubican hacia el extremo noroeste del asentamiento, en clara relación con la capilla (Elaboración y autoria de Abel Traslaviña, en base a información del Proyecto Arqueológico Tuti Antiguo). 

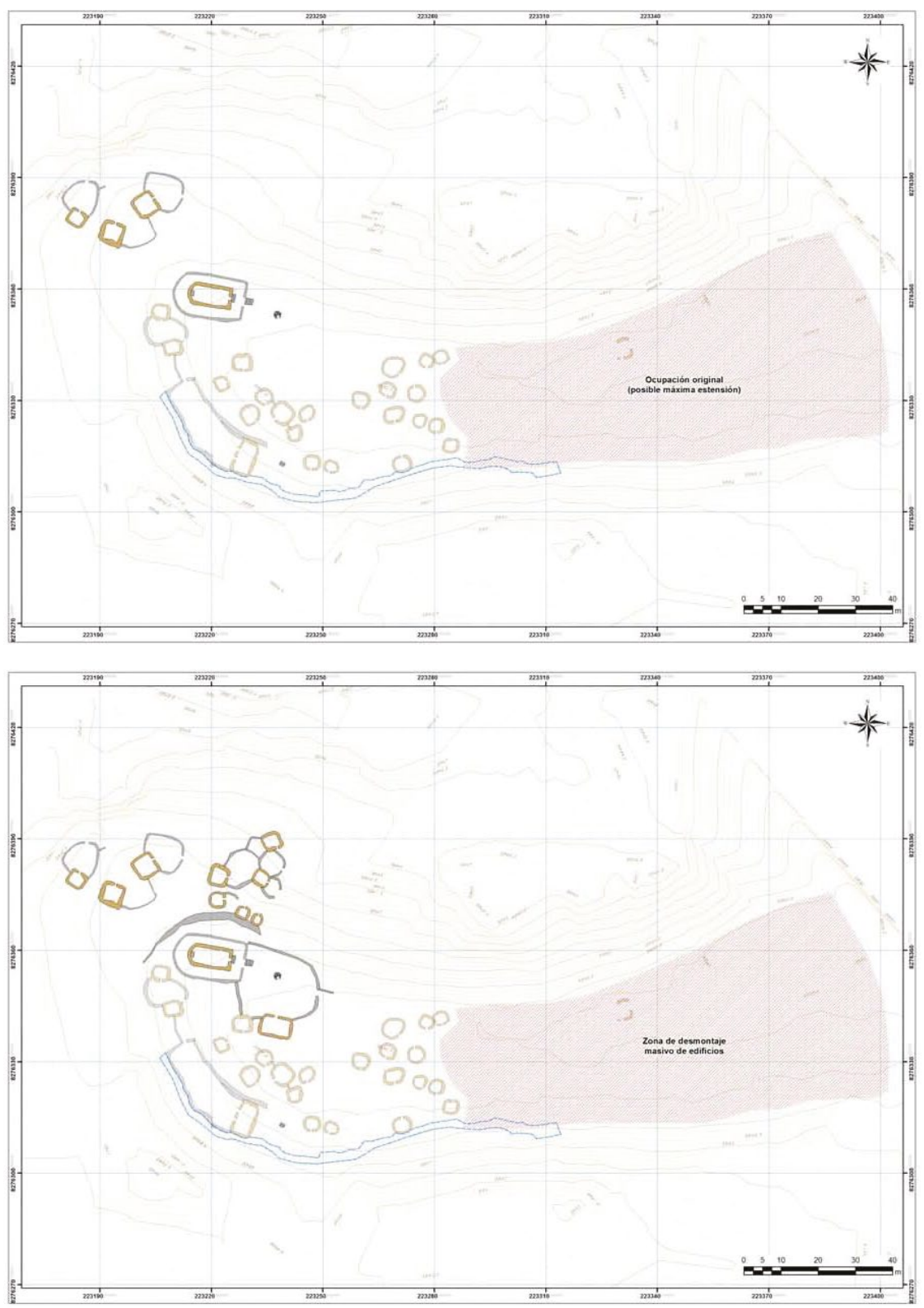

Figura 12. Arriba: Vista general del asentamiento durante la Sub-Fase 3c (Primer Momento) de ocupación. Nótese la construcción de la plataforma alrededor de la capilla y la peana. Abajo: Vista general del asentamiento durante la Sub-Fase 3c (Segundo Momento) de ocupación. Nótese la construcción de una nueva estructura asociada a la plaza (EST015), así como un nuevo grupo de Casas Tipo 1 hacia el norte de la capilla. Nótese que el área de ocupación inicial hacia el este tuvo que ser desmontada para dar paso a la última de las actividades (Elaboración y autoría: de Abel Traslaviña, sobre la base de información del Proyecto Arqueológico Tuti Antiguo). 


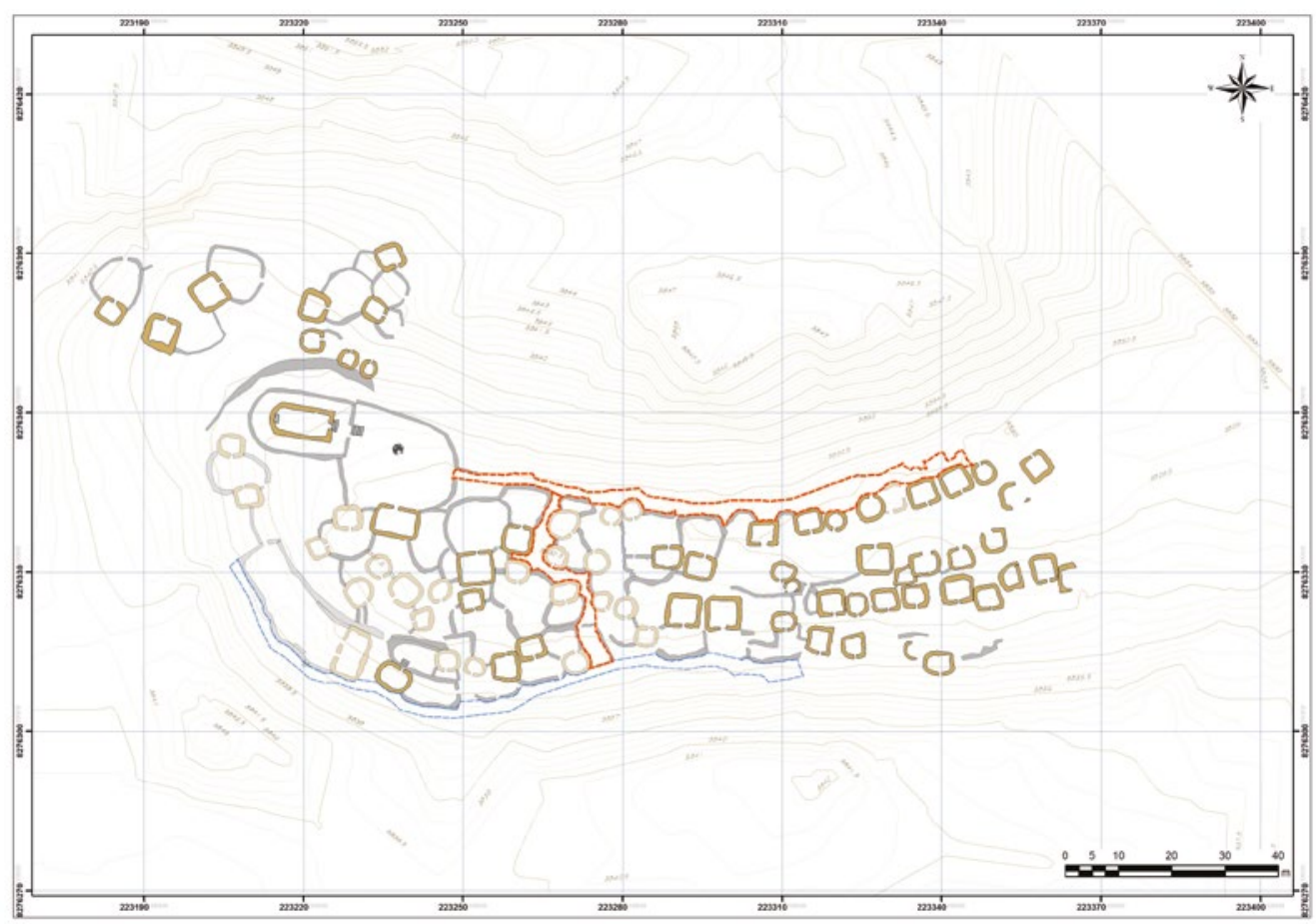

Figura 13. Vista general del asentamiento durante la Sub-Fase 3c (Tercer Momento) de ocupación. Nótese la construcción un nuevo grupo de Casas Tipo 3, asi como la Casa Tipo 2, adyacente a la plaza, al sendero norte y al sendero transversal (Elaboración y autoría de Abel Traslavina, a partir de información del Proyecto Arqueológico Tuti Antiguo).

Finalmente, se puede concluir que la transformación del espacio doméstico, evidenciada en la aparición de nuevas unidades arquitectónicas y la modificación de las ya existentes, estuvo estrechamente ligada a los cambios que sucedieron en el espacio público durante la ocupación peninsular. De esta manera, el centro del nuevo orden religioso y político en Malata se expresó en la tríada "Capilla-Plaza-Cabildo», que evoca el centro de las reducciones toledanas, establecidas años más tarde, siguiendo un diseño modular en donde la "manzana» se convierte en la unidad mínima de organización, mientras que a través de las calles se ordenan y controlan los flujos.

\section{Agradecimientos}

Quiero agradecer a todos los autores que comparten espacio en este volumen por su paciencia ante distintos imprevistos sucedidos a lo largo del camino para hacer realidad esta publicación. Asimismo, quisiera agradecer a Sandra Negro y Marco Curátola por confiar en nuestra propuesta para el simposio; a Steven Wernke, por incentivar en mí el interés en los estudios coloniales desde la arqueología y ser indirectamente gestor de nuestro simposio y de este volumen, además, claro está, de la información que se presenta en este artículo. Agradezco a mis grandes colegas y amigos Parker VanValkenburgh, Zachary Chase, Rosabella Álvarez-Calderón y Brendan Weaver. Muchas gracias por su incansable apoyo durante la organización del evento y la edición de este volumen. Finalmente, agradezco al equipo del Boletín de Arqueología PUCP, a sus directores Luis J. Castillo e Idilio Santillana, y a las editoras Francesca Fernandini y Ana Cecilia Mauricio por sus múltiples gestiones. 


\section{Notas}

${ }^{1}<$ http://lema.rae.es/drae/?val=casa $>$

\section{FUENTES MANUSCRITAS}

1501 Instrucciones al comendador fray Nicolás de Ovando, gobernador de las Islas y Tierra Firme del mar Océano, para el buen tratamiento de los indios, 16 de setiembre, Granada. En: http://www.biblioteca. tv/artman2/publish/1501_323/Instrucciones_al_comendador_fray_Nicol_s_de_Ovando_997.shtml. Consultado el 27 de diciembre del 2011.

1503 Instrucción para el gobernador y oficiales sobre el gobierno de las Indias. En: http://www.biblioteca. tv/artman2/publish/1503_262/Instrucci_n_para_el_gobernador_y_oficiales_sobre_e_998.shtml. Consultado el 27 de diciembre del 2011.

1509 Instrucciones a Diego Colón, gobernador de La Espańola, para que continúe con la formación de pueblos de indios, vigile que éstos no vendan sus propiedades e impida que algunos espańoles casados con indígenas, se apropien de la heredad de sus suegros, 3 de mayo, Valladolid. En: http://www.biblioteca. tv/artman2/publish/1509_294/Instrucciones_a_Diego_Col_oacute_n_gobernador_de_la_espa_ntilde. shtml. Consultado el 27 de diciembre del 2011.

1513 Las ordenanzas para el tratamiento de los indios, ordenadas por los Reyes Católicos, Isabel I de Castilla y Fernando II de Aragón, V de España, 23 de enero, Valladolid. En: http://www.biblioteca.tv/artman2/ publish/1512_306/Las_ordenanzas_para_el_tratamiento_de_los_indios_o_1119.shtml. Consultado el 27 de diciembre del 2011.

\section{REFERENCIAS}

Bonnier, E.

1997 Morfología del espacio aldeano y su expresión cultural en los Andes Centrales, en: E. Bonnier y H. Bischof (eds.), Archaologica peruana 2, 29-41, Sociedad Arqueológica Peruano-Alemana, Reiss-Museum Mannheim.

Brooks, S. O.

1998 Prehistoric Agricultural Terraces in the Río Japo Basin, Colca Valley, Peru, tesis doctoral, Department of Geography, University of Wisconsin-Madison, Madison.

DeMarrais, E.

2002 The architecture and organization of Xauxa settlements, en: T. D'Altroy y C. Hastorf eds., Empire and domestic economy, 115-153, Springer, New York.

Guerra Santander, E. M. y P. A. Aquize Cáceres

1996 Patrón arquitectónico y patrón de asentamiento del sitio prehispánico de Uskallacta Chivay (valle del Colca) - Arequipa, tesis de licenciatura, Facultad de Arqueología, Universidad Católica Santa María, Arequipa.

Heras, J.

1992 Aportes de los franciscanos a la evangelización del Perú. Provincia misionera de San Francisco Solano, Editora Latina, Lima.

Matos Mendieta, R.

1972 Wakan y wamalli: estudio arqueológico de dos aldeas rurales, en: J. V. Murra (ed.), Visita de la provincia de León de Huánuco en 1562, tomo II. Visita de los yacha y mitmaqkuna cuzqueños encomendados en Juan Sanchez Falcon, 367-382, Universidad Nacional Hermilio Valdizán, Facultad de Letras y Educación, Huánuco.

Meiklejohn, N.

1988 La iglesia y los Lupaqas de Chucuito durante la colonia, Centro de Estudios Rurales Andinos Bartolomé de Nash, D. J. las Casas, Cusco.

2002 The archaeology of space: places of power in the Wari empire, tesis doctoral, Department of Anthropology, University of Florida, Gainesville. 
Neira Avendaño, M.

1961 Los Collaguas, tesis de doctorado, Facultad de Letras, especialidad de Historia, Geografía y Ciencias Sociales, Universidad Nacional de San Agustín de Arequipa, Arequipa.

Pease, F.

1977 Del Tawantinsuyu a la historia del Perú, Serie Historia Andina 5, Instituto de Estudios Peruanos, Lima.

Saignes, T.

1991 Lobos y ovejas. Formación y desarrollo de los pueblos y comunidades en el sur andino (Siglos XVI-XX), en: S. Moreno y F. Salomon (comps.), Reproducción y transformación de las sociedades andinas siglos $X V I-X X, 91-135$, Ediciones Abya Yala, Quito.

Sánchez del Olmo, $S$.

2006 El texto como pretexto: Un relato histórico sobre la fundación de un pueblo de indios en Michoacán, en: J. J. Sánchez Baena y L. Provencio (eds.), El Mediterráneo y América, 765-779, Editora Regional de Murcia, Murcia.

Traslavińa, T. A.

2009 El sentido de orden: Implicancias de la transformación del espacio durante la colonia temprana en Malata, valle del Colca, Perú, ponencia presentada en el $73^{\circ}$ Congreso Anual de la Sociedad para Arqueología Americana, Atlanta, Georgia.

2016 El sentido de orden: Implicancias de la transformación del espacio durante la colonia temprana en Malata, Valle del Colca, Perú, tesis de licenciatura, Escuela Académico Profesional de Arqueología, Facultad de Ciencias Sociales, Universidad Nacional Mayor de San Marcos, Lima.

Traslavińa, A. y S. A. Wernke

2014 De antiguas normas y viejas formas: Reflexiones desde la arqueología sobre la transformación del espacio público - ritual durante la colonia temprana en el Valle del Colca, en: S. Negro y S. Amoros (eds.), Patrimonio, Identidad y Memoria, 59-82, Instituto de Investigación del Patrimonio Cultural/Universidad Ricardo Palma, Editorial Universitaria, Lima.

Vokral, E. V.

1991 Qoñi-Chiri. La organización de la cocina y estructuras simbólicas en el Altiplano del Perú, Ediciones Abya Yala, Quito.

Wernke, S. A.

2003 An Archaeo-History of Andean Community and Landscape: The Late Prehispanic and Early Colonial Colca Valley, Perú, tesis de doctorado, Department of Anthropology, University of Wisconsin, Madison.

2006 The Politics of Community and Inka Statecraft in the Colca Valley, Peru, Latin American Antiquity 17 (2), 177-208. https://doi.org/10.2307/25063046

2009 La interfaz política-ecológica en el valle del Colca durante la época inkaica, Andes 7: 587-614.

2013a Households in Transition: Reconstructing Domestic Organization at an Early Colonial Mission in the Andean Highlands, en: M. Oland, S. Hart y L. Frink (eds.), Decolonizing Indigenous Histories: Exploring Prehistoric/Colonial Transitions in Archaeology, 77-101, University of Arizona Press, Tucson.

2013b Negotiated Settlements: Andean Communities and Landscapes under Inka and Spanish Colonialism, University Press of Florida, Gainesville. https://doi.org/10.5744/florida/9780813042497.001.0001

Wernke, S. A. y E. Guerra Santander

2010 Proyecto Arqueológico Tuti Antiguo, Valle del Colca. Fase II: Excavación en el sitio de Malata, informe técnico de las labores del Proyecto Arqueológico Tuti Antiguo presentado al Instituto Nacional de Cultura, Arequipa.

Wernke, S. A., T. A. Traslavińa Arias y E. Guerra Santander

2012 La transformación del espacio arquitectónico en una doctrina temprana en el Valle del Colca, en: K. Lane y M. Luján Dávila (eds.), Arquitectura prehispánica tardía: Construcción y poder en los Andes Centrales, Universidad Católica Sedes Sapientiae, Lima.

Williams, T.

2009 The reestructuring of social spaces and practices in a trans-conquest andean settlement, tesis de bachiller en Antropología, Departamento de Antropología, Vanderbilt University, Nashville. 